\title{
Calculation of Rabbit and Simulator Worth in the HFIR Hydraulic Tube and Comparison with Measured Values
}

September 2005

\author{
Prepared by \\ C. O. Slater \\ Nuclear Science and Technology Division \\ R. T. Primm III \\ Research Reactors Division
}




\section{DOCUMENT AVAILABILITY}

Reports produced after January 1, 1996, are generally available free via the U.S. Department of Energy (DOE) Information Bridge:

Web site: http://www.osti.gov/bridge

Reports produced before January 1, 1996, may be purchased by members of the public from the following source:

National Technical Information Service

5285 Port Royal Road

Springfield, VA 22161

Telephone: 703-605-6000 (1-800-553-6847)

TDD: 703-487-4639

Fax: 703-605-6900

E-mail: info@ntis.fedworld.gov

Web site: http://www.ntis.gov/support/ordernowabout.htm

Reports are available to DOE employees, DOE contractors, Energy Technology Data Exchange (ETDE) representatives, and International Nuclear Information System (INIS) representatives from the following source:

Office of Scientific and Technical Information

P.O. Box 62

Oak Ridge, TN 37831

Telephone: $865-576-8401$

Fax: 865-576-5728

E-mail: reports@adonis.osti.gov

Web site: http://www.osti.gov/contact.html

This report was prepared as an account of work sponsored by an agency of the United States Government. Neither the United States government nor any agency thereof, nor any of their employees, makes any warranty, express or implied, or assumes any legal liability or responsibility for the accuracy, completeness, or usefulness of any information, apparatus, product, or process disclosed, or represents that its use would not infringe privately owned rights. Reference herein to any specific commercial product, process, or service by trade name, trademark, manufacturer, or otherwise, does not necessarily constitute or imply its endorsement, recommendation, or favoring by the United States Government or any agency thereof. The views and opinions of authors expressed herein do not necessarily state or reflect those of the United States Government or any agency thereof. 
Nuclear Science and Technology Division

\title{
CALCULATION OF RABBIT AND SIMULATOR WORTH IN THE HFIR HYDRAULIC TUBE AND COMPARISON WITH MEASURED VALUES
}

\author{
Charles O. Slater \\ R. Trent Primm III*
}

Date Published: September 2005

\author{
Prepared by \\ OAK RIDGE NATIONAL LABORATORY \\ P.O. Box 2008 \\ Oak Ridge, Tennessee 37831-6285 \\ managed by \\ UT-BATTELLE, LLC \\ for the \\ U.S. DEPARTMENT OF ENERGY \\ under contract DE-AC05-00OR22725
}

\footnotetext{
* Research Reactors Division
} 



\section{CONTENTS}

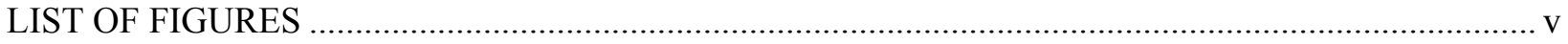

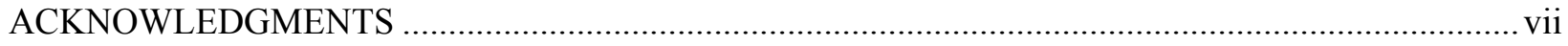

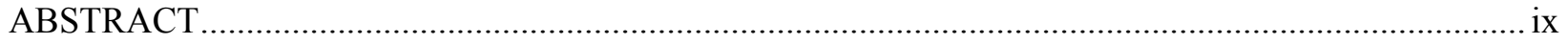

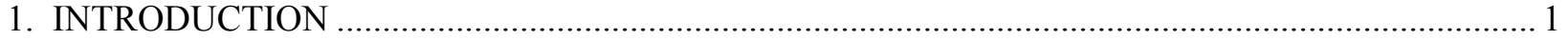

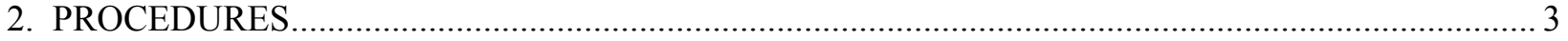

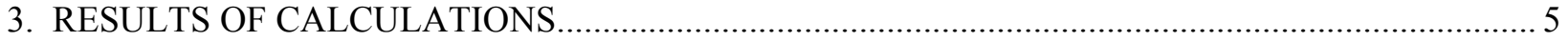

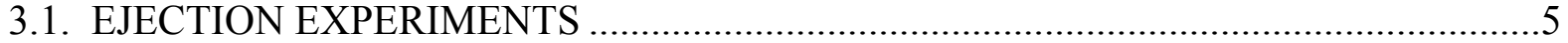

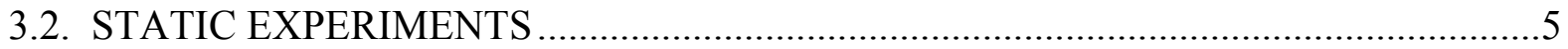

3.3. IMPACT OF MODELING ASSUMPTION REGARDING POSITION OF

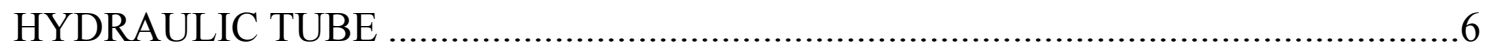

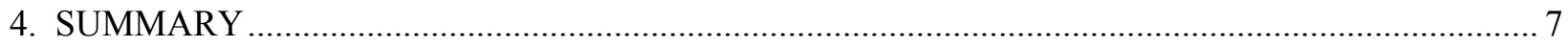

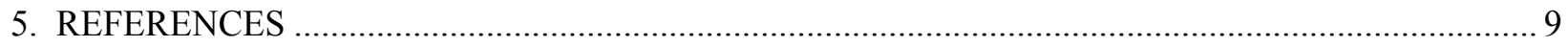

APPENDIX A. T. M. Sims Report on HFIR Reactivity Experiments................................................ 35

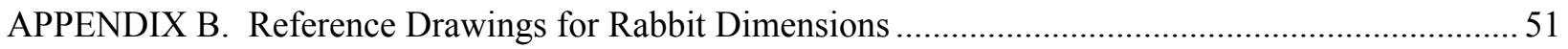

APPENDIX C. Descriptions of Input and Output Files for the Rabbit Worth Calculations .....................55 



\section{LIST OF FIGURES \\ (Figures are placed together after report text)}

Fig. 1. Plan view of the target region of the Xoubi MCNP model. 15

Fig. 2. Plan view of the Peplow MCNP model with the Cycle 400 target model incorporated. 16

Fig. 3. Plot of a target geometry showing a stack of nine assorted rabbits. .17

Fig. 4. Close-up plot of the top of white rabbit \#2 and the bottom of white rabbit \#1.

(Note that the scoops at the ends of the rabbits are filled with water when placed in the HFIR geometry.)

Fig. 5. Close-up plot of the top of white rabbit \#1 and the bottom of the $2 / 3$ black rabbit.

(Note that the scoops at the ends of the rabbits are filled with water when placed in the HFIR geometry.)

Fig. 6. Close-up plot of the top of the $2 / 3$ black rabbit. (Note that the scoops at the ends of the rabbits are filled with water when placed in the HFIR geometry.)

Fig. 7. Close-up plot of the top of the $2 / 3$ black rabbit and the bottom of the $1 / 3$ black rabbit. (Note that the scoops at the ends of the rabbits are filled with water when placed in the HFIR geometry.).

Fig. 8. Close-up plot of the top of the $1 / 3$ black rabbit and the bottom of the black rabbit.

(Note that the scoops at the ends of the rabbits are filled with water when placed in the

HFIR geometry.) .22

Fig. 9. Close-up plot of the top of the black rabbit and the bottom of the $1 / 3$ black rabbit.

(Note that the scoops at the ends of the rabbits are filled with water when placed in the

HFIR geometry.).

Fig. 10. Close-up plot of the top of the $2 / 3$ black rabbit and the bottom of the all-water

"rabbit". (Note that the scoops at the ends of the rabbits are filled with water when

placed in the HFIR geometry.) .24

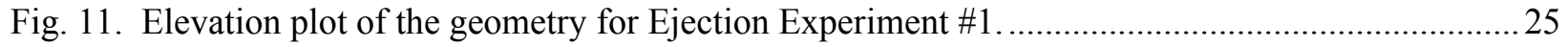

Fig. 12. Close-up plot of the hydraulic tube geometry for Ejection Experiment \#1 ..............................26

Fig. 13. Plan plot of the hydraulic tube geometry along the axial midplane for Ejection Experiment \#1 27

Fig. 14. Elevation plot of the geometry for Static Experiment \#6b. .28

Fig. 15. Plan plot of the hydraulic tube geometry along the axial midplane for Static Experiment \#6b. 
Fig. 16. Elevation plot of the geometry for Static Experiment \#7.

Fig. 17. Plan plot of the hydraulic tube geometry along the axial midplane for Static

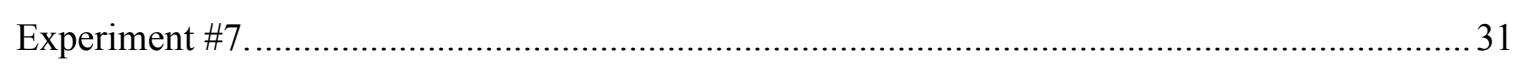

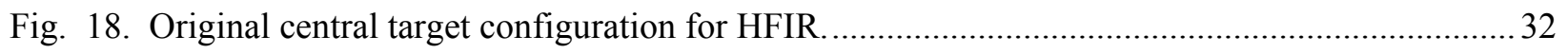

Fig. 19. Elevation plot of the central hydraulic tube geometry for Static Experiment \#6 ........................33

Fig. 20. Plan plot of the central hydraulic tube geometry along the axial midplane for Static Experiment

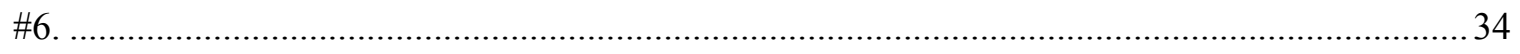




\section{ACKNOWLEDGMENTS}

The authors would like to acknowledge the technical reviews of this document that were performed by E. D. Blakeman and J. A. Bucholz both of Oak Ridge National Laboratory (ORNL). Also, the authors wish to acknowledge S. E. Burnette, ORNL, for providing programmatic support for this work. 



\begin{abstract}
To aid in the determinations of reactivity worths for target materials in a proposed High Flux Isotope Reactor (HFIR) target configuration containing two additional hydraulic tubes, the worths of cadmium rabbits within the current hydraulic tube were calculated using a reference model of the HFIR and the MCNP5 computer code. The worths were compared to measured worths for both static and ejection experiments. After accounting for uncertainties in the calculations and the measurements, excellent agreement between the two was obtained. Computational and measurement limitations indicate that accurate estimation of worth is only possible when the worth exceeds 10 cents. Results indicate that MCNP5 and the reactor model can be used to predict reactivity worths of various samples when the expected perturbations are greater than 10 cents. The level of agreement between calculation and experiment indicates that the accuracy of such predictions would be dependent solely on the quality of the nuclear data for the materials to be irradiated. Transients that are approximated by "piecewise static" computational models should likewise have an accuracy that is dependent solely on the quality of the nuclear data.
\end{abstract}





\section{INTRODUCTION}

The Research Reactors Division is reconfiguring the High Flux Isotope Reactor's (HFIR's) central target region to add two hydraulic rabbit tubes to be used in conjunction with the existing tube. These actions are being taken in connection with the need to increase the production of a specific radioisotope that has a half-life less than the duration of a typical HFIR fuel cycle. Startup safety procedures require that the reactivity worth of the simultaneous expulsion of all target material from the tubes be determined. Safety analyses for target irradiations performed in recent years have been based on a comparison of the absorption cross section of the new sample with that of cadmium rabbits for which worth measurements had been made (see Ref. 1, which is Appendix A). For the perturbation introduced by the use of two additional hydraulic tubes, the assumption of expulsion of cadmium rabbits, simultaneously, from all three fully loaded hydraulic tubes leads to a prompt reactivity excursion which is not allowed under the current operating procedures for the HFIR. Since measurements with cadmium rabbits could no longer serve as a bound for the safety analysis for experiment approval, it was deemed necessary that some other method be used to determine the worths of target materials within these tubes. The choice was made to determine the worths by computation. Thus, the measured worths of Ref. 1 are now to be used for validation of computational methods rather than for bounding safety assessments. The measurements serve as a benchmark for the computational tools. It is recommended that the reader examine Appendix A before continuing to the next section. 



\section{PROCEDURES}

The calculation of the rabbit worths was performed in several steps. HFIR MCNP ${ }^{2}$ models documented in Refs. 3 and 4 were the starting points for this study. Configuration-controlled versions of MCNP5 and nuclear data libraries were used to perform all calculations (ORNL Software Registration System identification number 854).

First, it was requested that the MCNP model used to calculate the worths be one resulting from the incorporation of the Cycle 400 target model from Ref. 3 into the model from Ref. 4. This task was performed through the incorporation of the necessary cells, surfaces, and materials in the reference model to form the new model. Plots were then made of the target geometry residing in both the Ref. 3 model and the new model, as shown in Figs. 1 and 2.

The new model differed from the old model in that there was an additional water mixture for the out-of-core regions. The water numbered 1 in the Ref. 3 model was renumbered 99, and material 1 from Ref. 4 became material 1 in the new model (this was in lieu of changing material 1 to material 3 in cells outside the target region in the Ref. 4 model). The plots of the two models thus show different colors for some regions because the material mappings were not one to one. Otherwise, the plots indicate that the Ref. 3 target model was successfully incorporated into the Ref. 4 model. The $S(\alpha, \beta)$ materials used for materials outside the core were also different (".01t" versus ".06t"). In addition, the new model used the newer materials found in the Xoubi file (ENDF6 versus ENDF5 materials). Eigenvalue calculations were also performed for the two models, and reaction rates were calculated. A few selected values are compared in Tables 1 and 2. The results are essentially the same, although there is about $2 \%$ difference in the average neutron flux in the flux trap region cell 719. Hence, the reference model for the rabbit worth calculations is verified.

Following the model verification, the rabbits were then modeled and placed in a stand-alone geometry for testing. Since the intent was to use arrays to model the experimental configurations, the geometry was tested using an array of nine stacked rabbits (the maximum number that could be placed in the tube). These rabbits included six types: (1) a black rabbit (an aluminum cylinder wrapped full length with a cadmium sheet within another aluminum cylinder), (2) a 1/3 black rabbit (an aluminum cylinder wrapped about $1 / 3$ length with a cadmium sheet within another aluminum cylinder), (3) a 2/3 black rabbit (an aluminum cylinder wrapped about $2 / 3$ length with a cadmium sheet within another aluminum cylinder), (4) a white rabbit (white rabbit \#1 — like the black rabbit with void replacing the cadmium sheet), (5) a second white rabbit (white rabbit \#2 - an aluminum cylinder with a voided interior), and (6) a water "rabbit" (a unit containing all water). Plots of the test geometry are shown in Figs. 3-10. As indicated in the figure captions, the scooped ends of the rabbits contain water (rather than void) when placed inside the hydraulic tube.

Figure 3 of Ref. 1 shows the length of a rabbit as $6.50875 \mathrm{~cm}(2.5625 \mathrm{in}$.). However, for the length of the target region in the hydraulic tube, nine rabbits $6.50748 \mathrm{~cm}$ (2.562 in.) in length would fit within that region. This is the same length given for a hydraulic tube capsule assembly at a HFIR Web site and elsewhere for an ORR irradiation capsule (see Appendix B). The diameter of the rabbit was not given but was assumed to be $0.9525 \mathrm{~cm}(0.375 \mathrm{in}$.) according to information from R. W. Hobbs (Ref. 5) and the fact that the same diameter and length were used for an ORNL drawing of an ORR rabbit. The drawing on the HFIR Website shows the diameter of the narrowest part of the fin to be $1.10998 \mathrm{~cm}(0.437 \mathrm{in}$.), and the diameter of the capsule is less than the fin diameter.

For the worth calculations that are reported subsequently, the rabbits were modeled with the shorter length $(6.50748 \mathrm{~cm})$, and the interior cells of the hydraulic tube were replaced by the rabbit arrays or 
simulators. Figures 11-17 show plots of the geometry for three experiments. Also, the control rod position was changed to $44.45 \mathrm{~cm}$ (17.5 in.) to correspond to the position given in Ref. 1.

The static and ejection experiments are described in Table 3. Eigenvalue calculations were performed for each experiment mockup along with a calculation for a reference mockup in which the hydraulic tube was filled with water. Calculations were performed with a modified version of the MCNP5 code for which the format in one subroutine was changed to print more digits for the final $\mathrm{k}_{\mathrm{eff}}$ values. The altered subroutine was crit1_mod.F90, which prints the data to the computer screen unless the data is captured in a log file. The format of the write statement was the only change made to the program. 


\section{RESULTS OF CALCULATIONS}

The calculated $k_{\text {eff }}$ value for each experiment was compared with that calculated for the reference experiment (all water in the hydraulic tube) to determine the worth of the rabbits or simulators. Approximately 50 million histories were run, and all standard deviations were about 0.00013 , which was on the order of some $\Delta \mathrm{k}_{\text {eff }}$ values. Results, converted to cents using 0.0076 as the $\beta$ for HFIR (Ref. 6), are given in Table 4. Input and output files for the calculations are described in Appendix C.

\subsection{EJECTION EXPERIMENTS}

While the signs on the reactivity worths are the same for the calculated and measured values for the ejection experiments, the agreement between the calculated and measured values, if evaluated on the basis of $\mathrm{C} / \mathrm{E}$ ratio, is poor. Reference 1 provides some explanation for the level of disagreement. All of the ejection experiments were of low worth, the largest being 6.1 cents. Ref. 1 states that "no attempt was made to check the reproducibility of the experimental results" and also notes that "one cent corresponds to only $\sim 0.006$ inches on the regulating rod. On this basis, the accuracy, particularly of the small values, is somewhat questionable."

Indicators for control and safety element positions record to 0.01 inches or approximately 1.6 cents at the critical position noted in Ref. 1. It is an operator function to establish symmetry in control and safety plate withdrawal positions. The uncertainty in symmetric control/safety element positions is not stated in Ref. 1; however, the Monte Carlo model assumes symmetry of control and safety plates.

As stated previously, the Monte Carlo calculations were converged to a standard deviation of 0.00013 in the multiplication factor. Since the calculated worth of an expelled target is the difference between two calculated k-effectives, the standard deviation of the difference is 0.00026 or 3.4 cents. Table 4 shows that most of the calculations and measurements agree to within one standard deviation of the calculated worth. If the experimental measurement is assumed to have a standard deviation of 1.6 cents, then the difference between calculation and measurement should have a standard deviation of 5.0 cents. All differences between calculations and measurements agree at this level. Computational and measurement limitations indicate that accurate estimation of worth is only possible when the worth exceeds 10 cents.

\subsection{STATIC EXPERIMENTS}

Excellent agreement is seen for the static experiments where many of the $\mathrm{C} / \mathrm{E}$ values agree within $10 \%$ and all of the differences between calculation and experiment agree to within one standard deviation. Results indicate that MCNP5 and the reactor model can be used to predict reactivity worths of various samples when the expected perturbations are greater than 10 cents. The level of agreement between calculation and experiment indicate that the accuracy of such predictions would be dependent solely on the quality of the nuclear data for the materials to be irradiated. Transients that are approximated by "piecewise static" computational models should likewise have an accuracy that is dependent solely on the quality of the nuclear data. 


\subsection{IMPACT OF MODELING ASSUMPTION REGARDING POSITION OF HYDRAULIC TUBE}

The worth calculations were performed for rabbits situated in an offset hydraulic tube in the Xoubi target model. Since the measurements were performed for a central hydraulic tube (Fig. 18), the calculated worths could be somewhat different from those shown in Table 4. Therefore, the effect of the central versus the offset hydraulic tube was studied for static experiment \#6 (nine black rabbits). The dummy aluminum target in the center of the model was replaced with a hydraulic tube model, and the offset hydraulic tube was returned to its original mockup as in the Xoubi model. Two MCNP models were constructed with the hydraulic tube containing nine black rabbits or water. Plots of the geometry for the black rabbits are shown in Figs. 19 and 20. The elevation view plot in Fig. 19 shows the nine black rabbits in the central tube and nine dummy capsules (Al-1100 inside Al-1100) in the offset hydraulic tube to the left. MCNP Eigenvalue calculations were performed using approximately 50 million histories. The calculations gave $\mathrm{k}_{\text {eff }}$ values of 0.997290523 for the nine-black-rabbit configuration and 1.000638033 for the water-filled tube configuration, both with standard deviations of 0.00013 . Again, treating the water-filled tube configuration as the reference case, one finds the worth of the nine-black-rabbit configuration to be -44.05 cents. The $\mathrm{C} / \mathrm{E}$ value is 0.92 . The absolute difference between the calculated and measured results is greater than 3.4 cents (the standard deviation of the calculation) but less than 5.0 cents (the sum of the standard deviations of the calculated and measured results). Actually, with respect to the offset hydraulic tube configurations, the $\mathrm{k}_{\text {eff }}$ values for the central hydraulic tube configurations decreased by $0.03 \%$ for the water-filled tube configuration and $0.003 \%$ for the nine black rabbit configuration. Yet, the worth changed about $9 \%$. Nevertheless, based on this result for the central hydraulic tube, one would expect the effects of the central hydraulic tube on the calculations for the other experiments to be within the combined errors of the calculations and the experiments. 


\section{SUMMARY}

Reactivity worths of several cadmium rabbit configurations within the HFIR were calculated and compared to measured results to benchmark the MCNP5 code for calculating such worths. The good agreement with measurements - all values of differences between calculation and experiment are less

than the expected one standard deviation for that parameter - give confidence that MCNP5 can be used for such calculations. 



\section{REFERENCES}

1. Personal communication from T. M. Sims to R. V. McCord, internal memorandum, "Results of Preliminary Reactivity Experiments - HFIR Hydraulic Tube", March 31, 1967.

2. X-5 Monte Carlo Team, MCNP - A General Monte Carlo N-Particle Transport Code, Version 5, Los Alamos National Laboratory Report, Vol. I (LA-UR-03-1987), Vol. II (LA-CP-03-0245), and Vol. III (LA-CP-03-0284), April 24, 2003.

3. N. Xoubi and R. T. Primm III, 3-D MCNP Model and Benchmarking of the High Flux Isotope Reactor Cycle 400, ORNL/TM-2004/251.

4. D. E. Peplow, A Computational Model of the High Flux Isotope Reactor for the Calculations of Cold Source, Beam Tube, and Guide Hall Nuclear Parameters, ORNL/TM-2004/237, November 2004.

5. Personal communication from R. W. Hobbs to R. T. Primm III, March 30, 2005.

6. R. D. Cheverton and T. M. Sims, HFIR Core Nuclear Design, ORNL-4621 (Appendix A.9), July 1971. 

Table 1. Comparison of fission and aluminum capture rates $\left(\mathrm{cm}^{-3} \cdot \mathrm{s}^{-1}\right)$ in fueled regions

\begin{tabular}{|l|c|c|c|}
\hline \multirow{2}{*}{ Core Region } & \multicolumn{2}{|c|}{ Fission and Aluminum Capture Rate } & \multirow{2}{*}{ Ratio } \\
\cline { 2 - 3 } & Xoubi Model & New Model & 0.997 \\
\hline Inner Element Region 1 & $6.3885-7(0.0006)^{a}$ & $6.3696-7(0.0006)$ & 0.998 \\
\hline Inner Element Region 2 & $5.0468-7(0.0006)$ & $5.0350-7(0.0006)$ & 0.998 \\
\hline Inner Element Region 3 & $4.0819-7(0.0006)$ & $4.0753-7(0.0006)$ & 0.999 \\
\hline Inner Element Region 4 & $3.2930-7(0.0005)$ & $3.2888-7(0.0005)$ & 0.999 \\
\hline Inner Element Region 5 & $2.8382-7(0.0005)$ & $2.8352-7(0.0005)$ & 0.998 \\
\hline Inner Element Region 6 & $2.8324-7(0.0005)$ & $2.8275-7(0.0005)$ & 0.999 \\
\hline Inner Element Region 7 & $3.1093-7(0.0005)$ & $3.1057-7(0.0005)$ & 0.998 \\
\hline Inner Element Region 8 & $3.6447-7(0.0005)$ & $3.6385-7(0.0005)$ & 0.997 \\
\hline Outer Element Region 1 & $3.3417-7(0.0005)$ & $3.3303-7(0.0005)$ & 0.998 \\
\hline Outer Element Region 2 & $2.7014-7(0.0005)$ & $2.6947-7(0.0005)$ & 0.998 \\
\hline Outer Element Region 3 & $2.2363-7(0.0005)$ & $2.2329-7(0.0005)$ & 0.999 \\
\hline Outer Element Region 4 & $1.8676-7(0.0004)$ & $1.8656-7(0.0004)$ & 0.999 \\
\hline Outer Element Region 5 & $1.7093-7(0.0004)$ & $1.7075-7(0.0004)$ & 1.001 \\
\hline Outer Element Region 6 & $1.7855-7(0.0004)$ & $1.7878-7(0.0004)$ & 1.005 \\
\hline Outer Element Region 7 & $1.9648-7(0.0005)$ & $1.9739-7(0.0005)$ & 1.007 \\
\hline Outer Element Region 8 & $2.1575-7(0.0005)$ & $2.1720-7(0.0005)$ & 1.008 \\
\hline Outer Element Region 9 & $2.4005-7(0.0005)$ & $2.4186-7(0.0005)$ & \\
\hline
\end{tabular}

${ }^{a}$ Read as $6.3885 \times 10^{-7}$ with a fractional standard deviation of 0.0006 .

Table 2. Comparison of average total neutron fluxes in the flux trap regions

\begin{tabular}{|c|c|c|c|}
\hline \multirow{2}{*}{ Cell } & \multicolumn{2}{|c|}{ Average Fluxes $\left(\mathrm{cm}^{-2} \cdot \mathrm{s}^{-1}\right)$} & \multirow{2}{*}{ Ratio } \\
\cline { 2 - 3 } & Xoubi Model & New Model & 1.001 \\
\hline 579 & $7.2681-4(0.0083)^{a}$ & $7.2775-4(0.0084)$ & 1.009 \\
\hline 649 & $7.1645-4(0.0084)$ & $7.2325-4(0.0084)$ & 0.982 \\
\hline 719 & $7.3024-4(0.0137)$ & $7.1677-4(0.0138)$ & 1.003 \\
\hline All Three & $7.2265-4(0.0056)$ & $7.2446-4(0.0056)$ & \\
\hline
\end{tabular}

${ }^{a}$ Read as $7.2681 \times 10^{-4}$ with a fractional standard deviation of 0.0083 . 
Table 3. Description of the experimental mockups within the HFIR hydraulic tube

\begin{tabular}{|c|c|}
\hline Experiment & Description $^{a}$ \\
\hline \multicolumn{2}{|r|}{ Ejection Experiments } \\
\hline 0 & $9 \mathrm{H} 2 \mathrm{O}$ \\
\hline 1 & 4W1-1B-4W1 \\
\hline $1 \mathrm{~b}$ & $4 \mathrm{~W} 2-1 \mathrm{~B}-4 \mathrm{~W} 2$ \\
\hline 2 & 4W1-1/3B-4W1 \\
\hline 3 & $4 \mathrm{~W} 1-2 / 3 \mathrm{~B}-4 \mathrm{~W} 1$ \\
\hline 4 & $4 \mathrm{~W} 1-2 / 3 \mathrm{~B}-4 \mathrm{H} 2 \mathrm{O}$ \\
\hline 5 & 2/3B-8H2O \\
\hline 6 & 9W1 \\
\hline $6 b$ & 9W2 \\
\hline \multicolumn{2}{|r|}{ Static Experiments } \\
\hline 0 & $9 \mathrm{H} 2 \mathrm{O}$ \\
\hline 1 & $4 \mathrm{H} 2 \mathrm{O}-1 / 3 \mathrm{~B}-4 \mathrm{H} 2 \mathrm{O}$ \\
\hline 2 & $4 \mathrm{H} 2 \mathrm{O}-1 \mathrm{~B}-4 \mathrm{H} 2 \mathrm{O}$ \\
\hline 3 & $3 \mathrm{H} 2 \mathrm{O}-2 \mathrm{~B}-4 \mathrm{H} 2 \mathrm{O}$ \\
\hline 4 & $3 \mathrm{H} 2 \mathrm{O}-3 \mathrm{~B}-3 \mathrm{H} 2 \mathrm{O}$ \\
\hline 5 & $1 \mathrm{H} 2 \mathrm{O}-6 \mathrm{~B}-2 \mathrm{H} 2 \mathrm{O}$ \\
\hline 6 & $9 \mathrm{~B}$ \\
\hline $6 \mathrm{~b}$ & "9B" \\
\hline 7 & "9W" \\
\hline
\end{tabular}

${ }^{a}$ The components are as follows:

H2O: All-water rabbits that are $6.50748 \mathrm{~cm}$ long.

$\mathrm{W} 1$ : White rabbits that are $6.50748 \mathrm{~cm}$ long with aluminum plug inside.

W2: White rabbits that are $6.50748 \mathrm{~cm}$ long with voided inside.

B: Black rabbits that are $6.50748 \mathrm{~cm}$ long containing a plug of cadmium over aluminum.

1/3B: Partially black rabbits that are $6.50748-\mathrm{cm}$-long containing a plug having a

1.84912-cm-wide cadmium sheet around a 5.45592-cm-long aluminum rod.

2/3B: Partially black rabbits that are 6.50748-cm-long containing a plug having a

3.6957-cm-wide cadmium sheet around a 5.45592-cm-long aluminum rod.

"9B": A plug simulating nine black rabbits with a 58.56732-cm-long aluminum tube plugged with a cadmium sheet surrounding a 58.27522-cm-long aluminum rod.

"9W": A plug simulating nine white rabbits with a 58.56732-cm-long aluminum tube containing a 58.27522-cm-long void chamber. 
Table 4. Comparison of calculated and measured worths

\begin{tabular}{|c|c|c|c|c|c|c|}
\hline \multirow[b]{2}{*}{ Experiment } & \multirow[b]{2}{*}{$\mathrm{k}_{\mathrm{eff}}$} & \multirow{2}{*}{$\begin{array}{c}\text { Calculated } \\
\text { Worth (cents) }\end{array}$} & \multirow{2}{*}{$\begin{array}{c}\text { Measured } \\
\text { Worth (cents) }\end{array}$} & \multirow[t]{2}{*}{$\mathrm{C} / \mathrm{E}$} & \multicolumn{2}{|c|}{$|\mathrm{C}-\mathrm{E}|>$} \\
\hline & & & & & 3.4 cents & 5.0 cents \\
\hline \multicolumn{7}{|c|}{ Ejection Experiments } \\
\hline 0 & 1.0009295 & - & - & - & - & - \\
\hline 1 & 1.0000940 & -10.99 & -6.1 & 1.80 & Yes & No \\
\hline $1 \mathrm{~b}$ & 1.0001227 & -10.62 & -6.1 & 1.74 & Yes & No \\
\hline 2 & 1.0009200 & -0.125 & -0.8 & 0.16 & No & No \\
\hline 3 & 1.0003378 & -7.79 & -3.5 & 2.22 & Yes & No \\
\hline 4 & 1.0003966 & -7.01 & -5.4 & 1.30 & No & No \\
\hline 5 & 1.0007886 & -1.85 & $\begin{array}{ll}-1 \\
-1.1\end{array}$ & 1.69 & No & No \\
\hline 6 & 1.0010753 & +1.92 & +3.5 & 0.55 & No & No \\
\hline $6 \mathrm{~b}$ & 1.0009539 & +0.321 & +3.5 & 0.092 & No & No \\
\hline \multicolumn{7}{|c|}{ Static Experiments } \\
\hline 1 & 1.0006211 & -4.06 & -2.5 & 1.62 & No & No \\
\hline 2 & 0.9998347 & -14.4 & -10.0 & 1.44 & Yes & No \\
\hline 3 & 0.9994268 & -19.77 & -18.3 & 1.08 & No & No \\
\hline 4 & 0.9988813 & -26.95 & -26.5 & 1.02 & No & No \\
\hline 5 & 0.9977537 & -41.79 & -41.5 & 1.01 & No & No \\
\hline 6 & 0.9972627 & -48.25 & -48.0 & 1.01 & No & No \\
\hline $6 \mathrm{~b}$ & 0.9969483 & -52.38 & -48.0 & 1.09 & Yes & No \\
\hline 7 & 1.0011001 & +2.24 & +5.0 & 0.45 & No & No \\
\hline
\end{tabular}

${ }^{a}$ The worth is calculated as follows: worth $=100\left(\mathrm{k}_{\mathrm{eff}}-\mathrm{k}_{\mathrm{ref}}\right) / 0.0076$, where $\mathrm{k}_{\mathrm{ref}}$ is the multiplication factor when the tube is filled with water and 0.0076 is the assumed $\beta$ value for HFIR. Based on a standard deviation of 0.00013 for each Monte Carlo estimate of k-effective, the standard deviation of a difference between k-effective values would be 0.00026 . One standard deviation for the calculated worth would be 3.4 cents. 



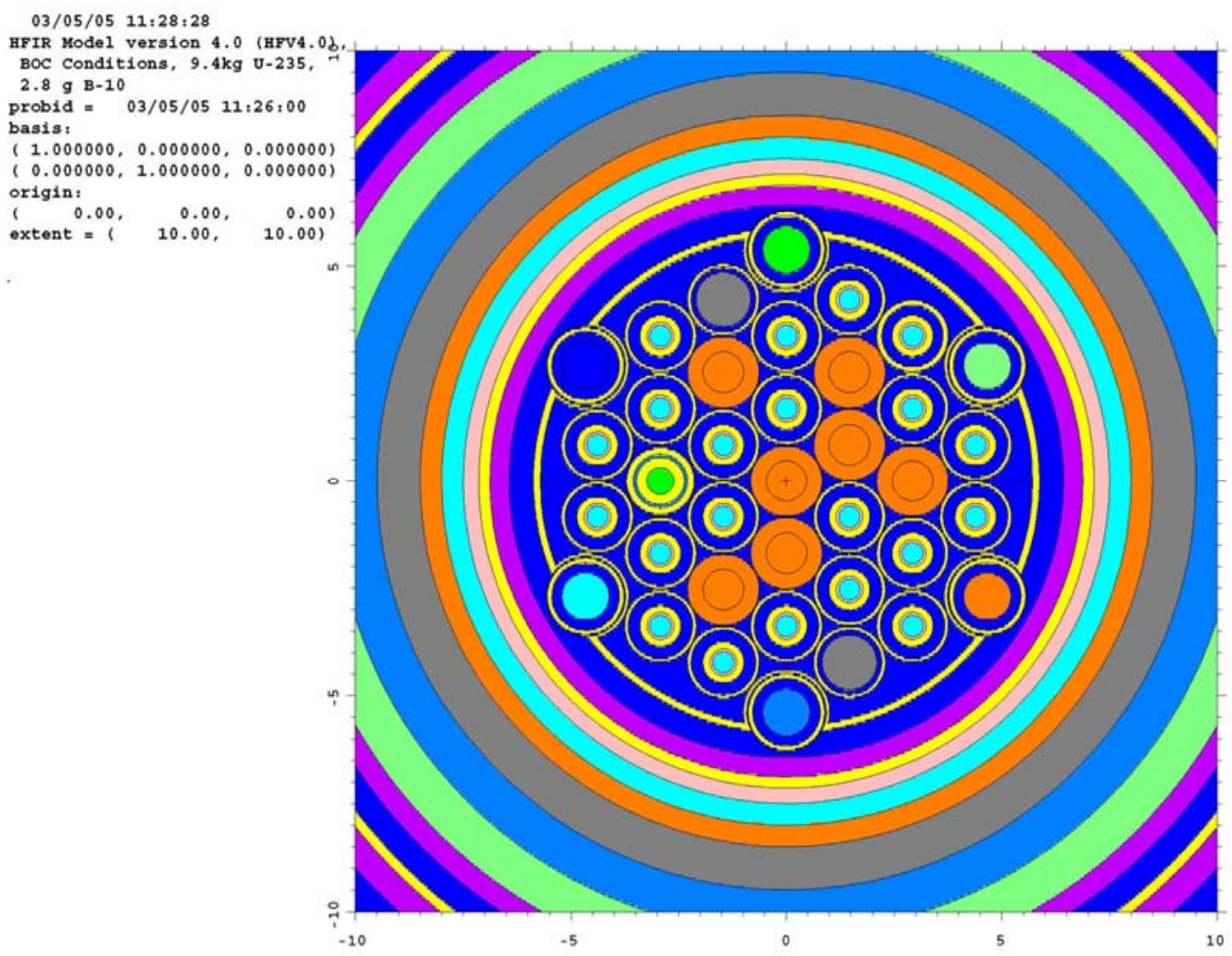

Fig. 1. Plan view of the target region of the Xoubi MCNP model. 


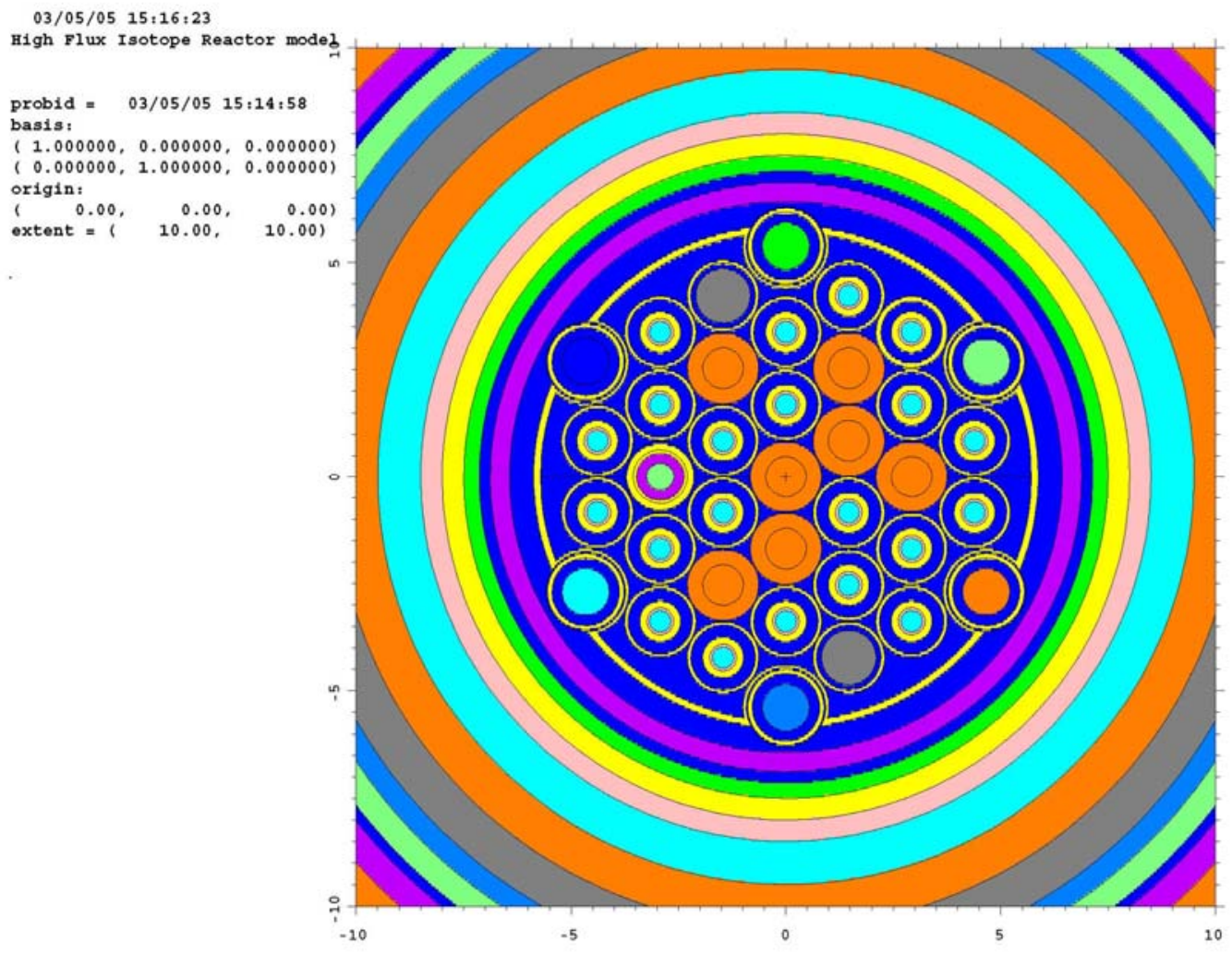

Fig. 2. Plan view of the Peplow MCNP model with the Cycle 400 target model incorporated. 


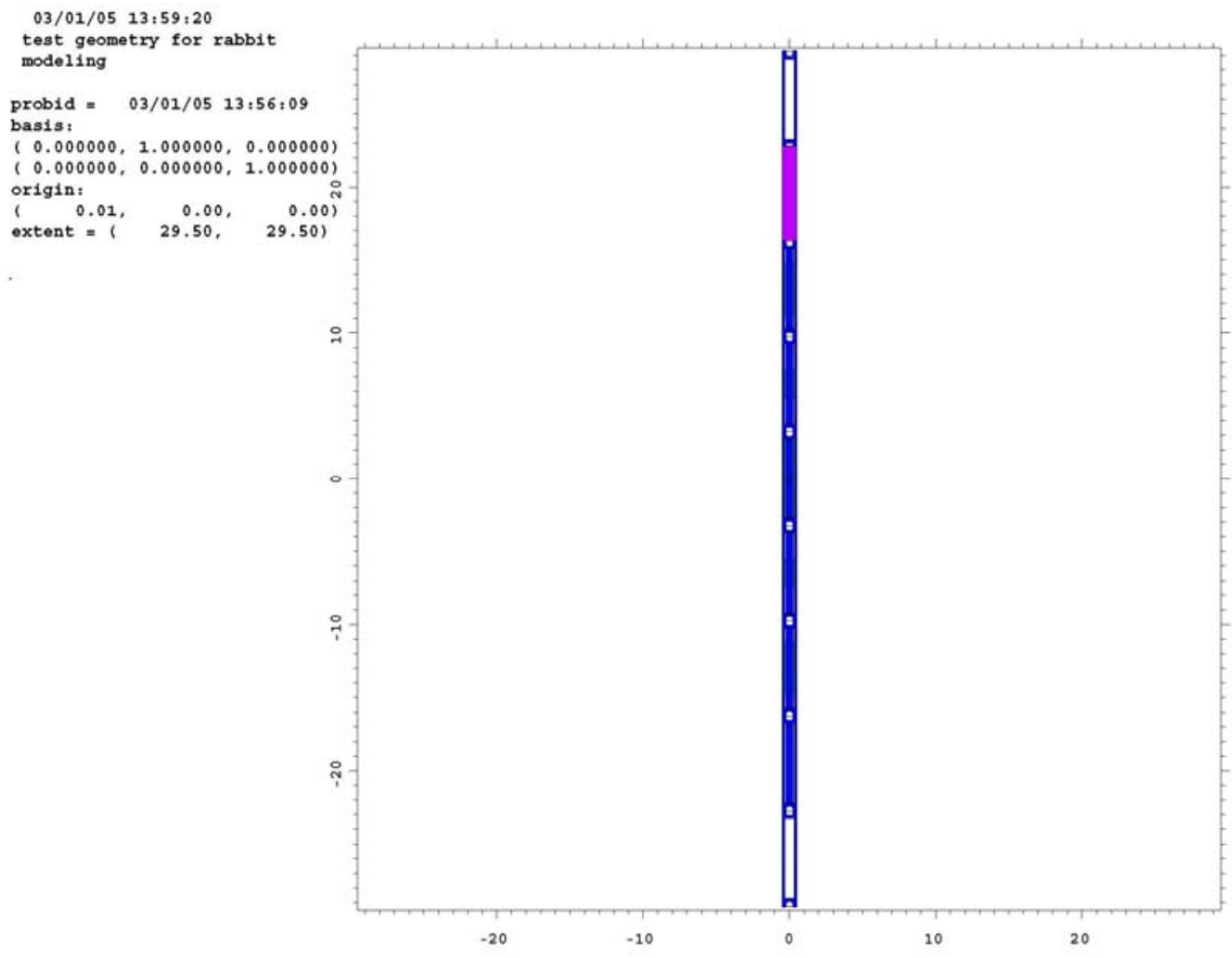

Fig. 3. Plot of a target geometry showing a stack of nine assorted rabbits. (Note that the scoops at the ends of the rabbits are filled with water when placed in the HFIR geometry.) 


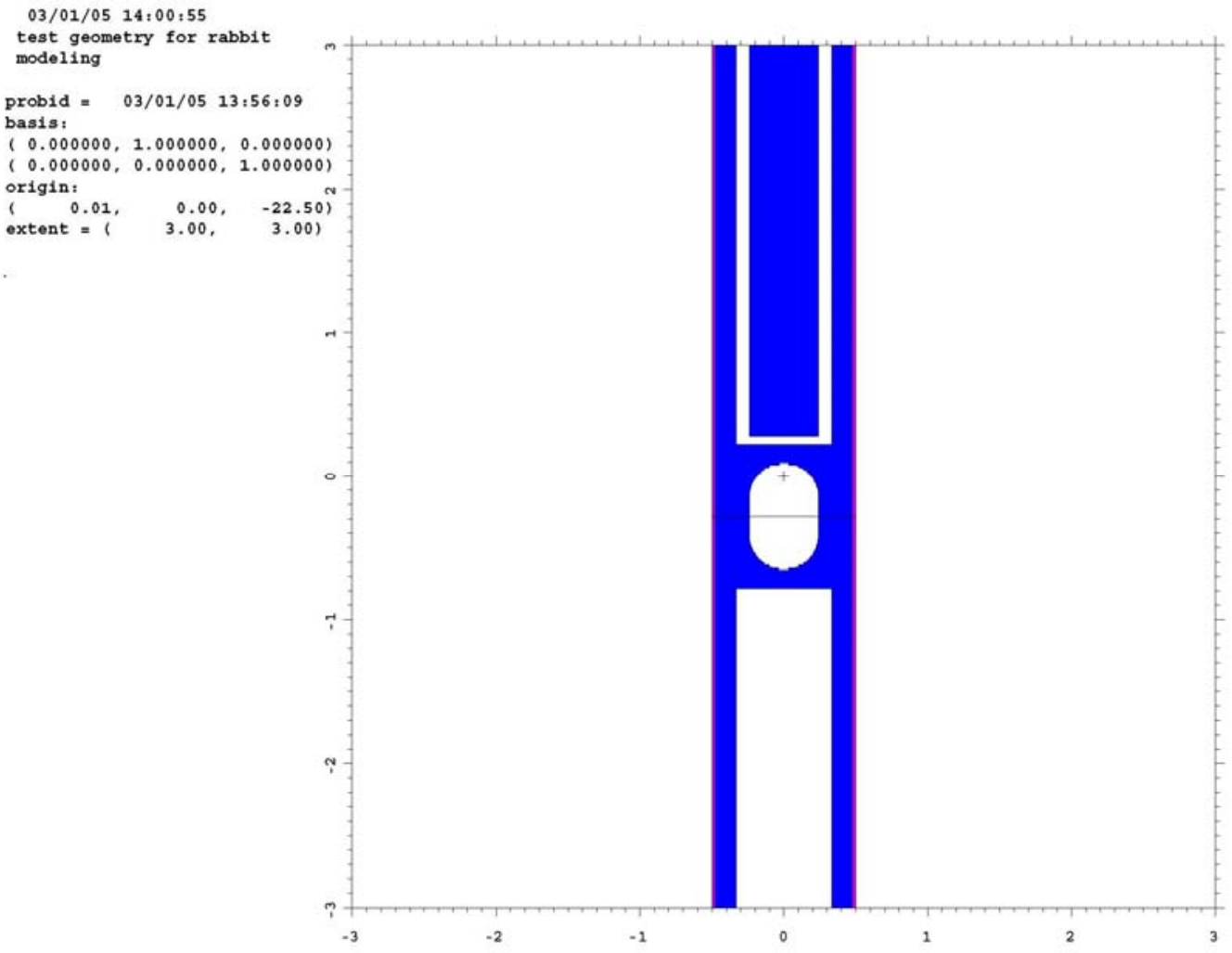

Fig. 4. Close-up plot of the top of white rabbit \#2 and the bottom of white rabbit \#1. (Note that the scoops at the ends of the rabbits are filled with water when placed in the HFIR geometry.) 


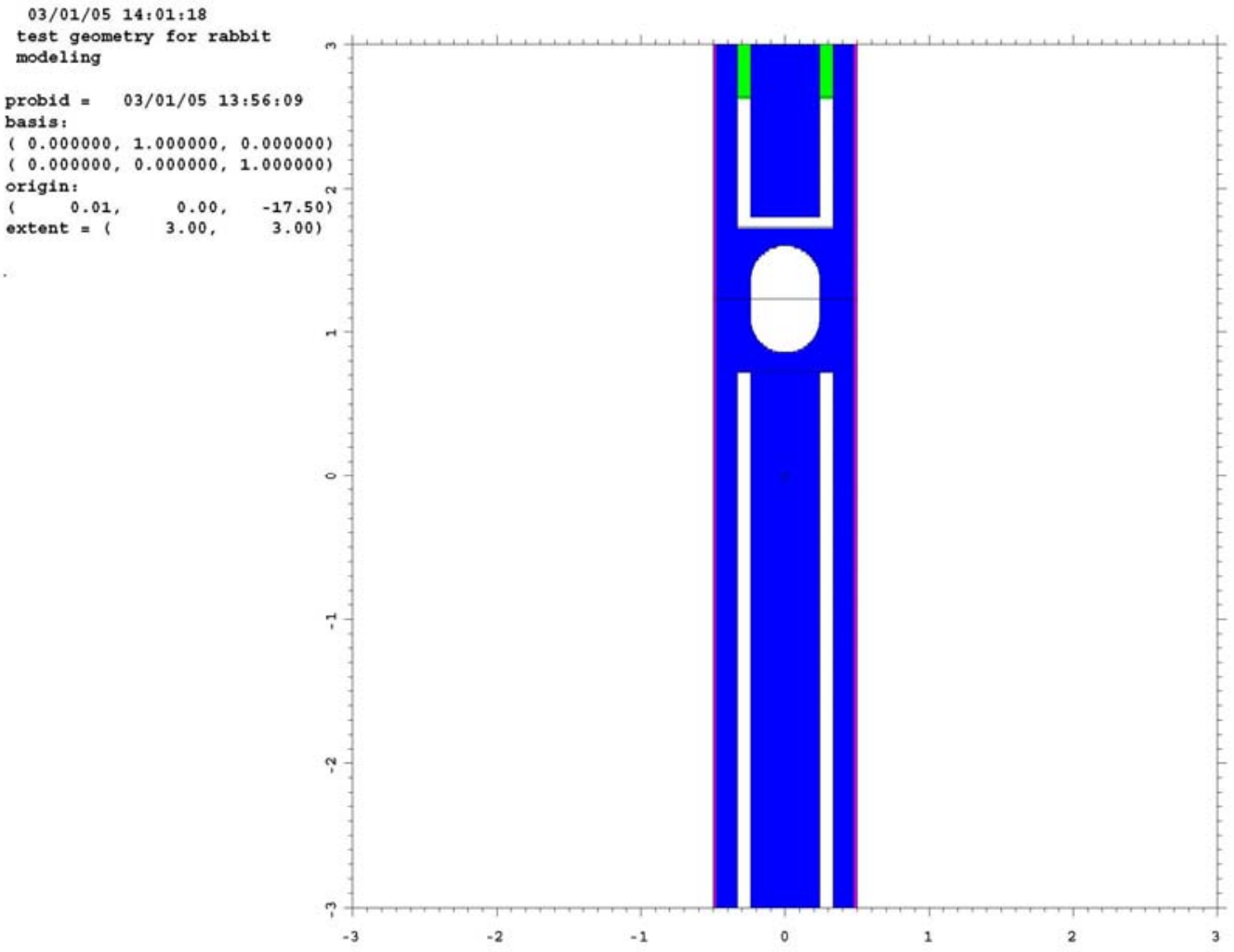

Fig. 5. Close-up plot of the top of white rabbit $\# 1$ and the bottom of the $2 / 3$ black rabbit. (Note that the scoops at the ends of the rabbits are filled with water when placed in the HFIR geometry.) 


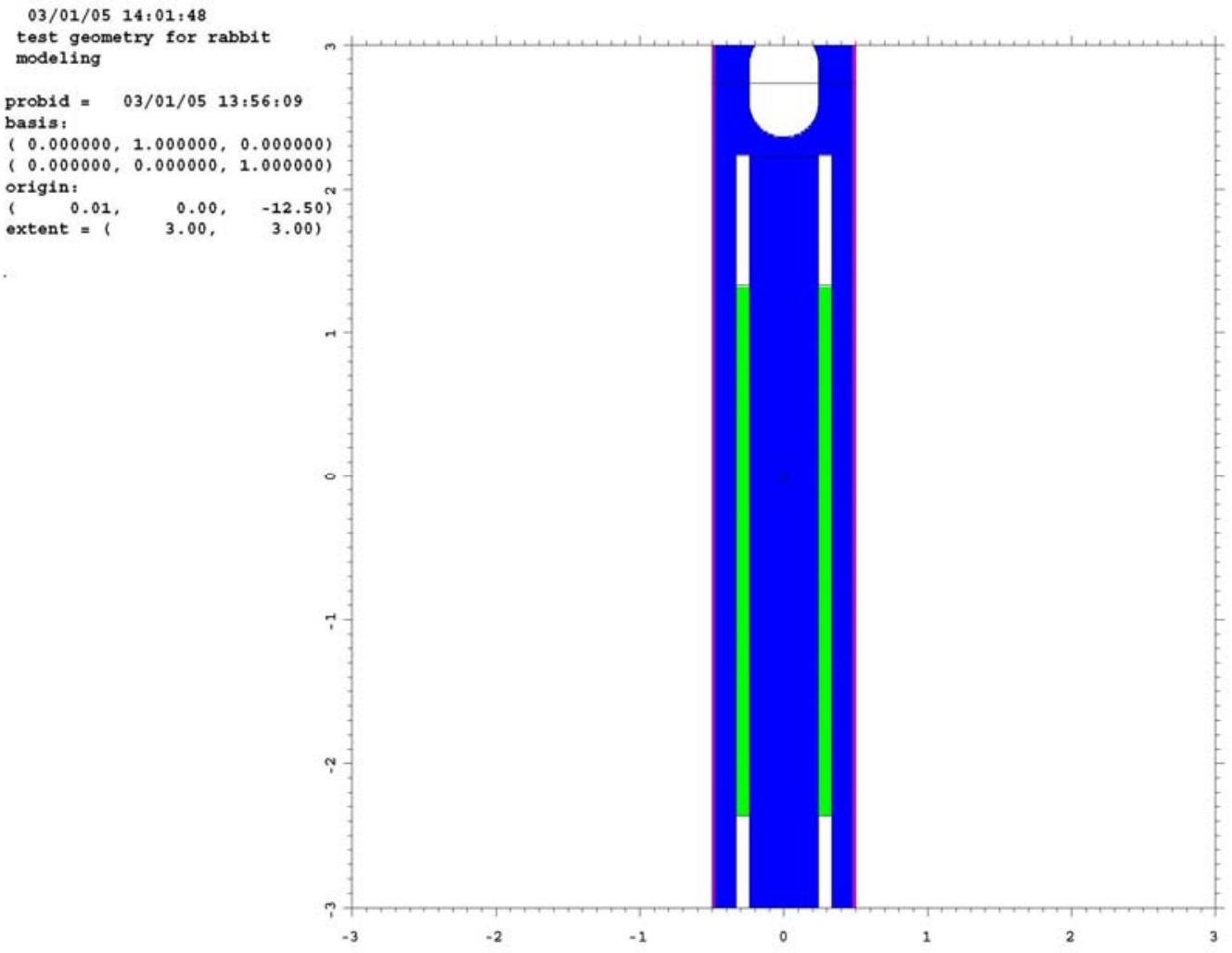

Fig. 6. Close-up plot of the top of the $2 / 3$ black rabbit. (Note that the scoops at the ends of the rabbits are filled with water when placed in the HFIR geometry.) 


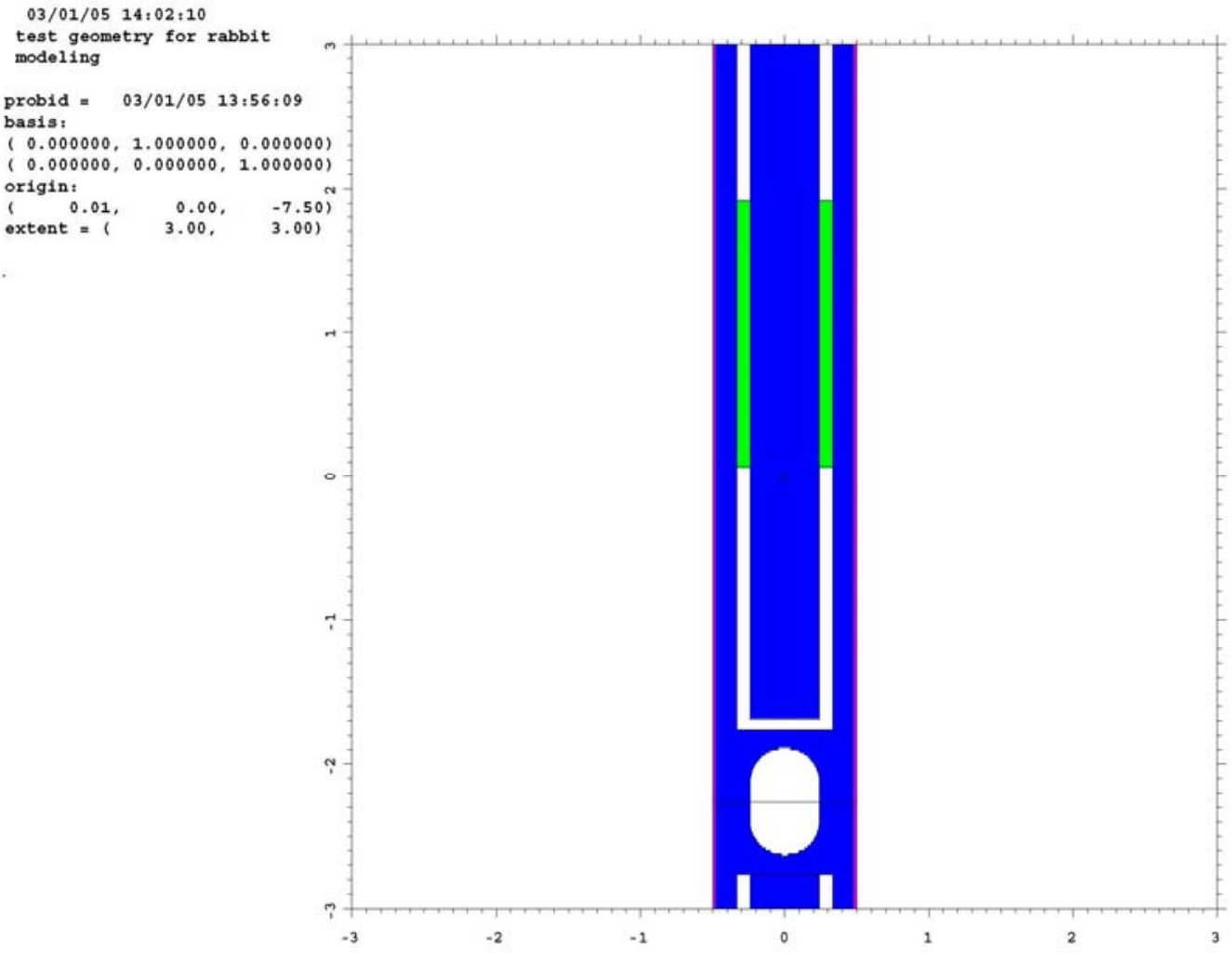

Fig. 7. Close-up plot of the top of the $2 / 3$ black rabbit and the bottom of the $1 / 3$ black rabbit. (Note that the scoops at the ends of the rabbits are filled with water when placed in the HFIR geometry.) 


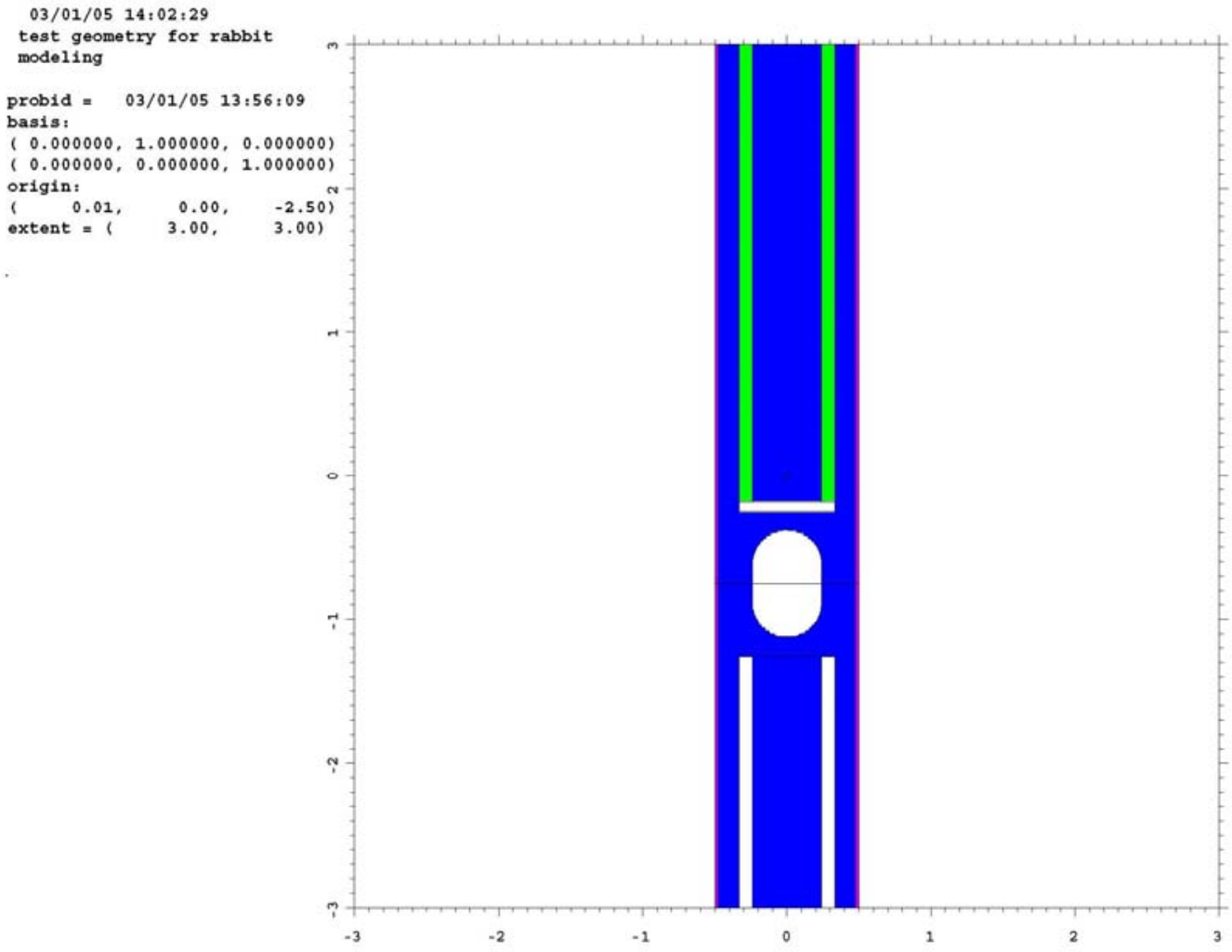

Fig. 8. Close-up plot of the top of the $1 / 3$ black rabbit and the bottom of the black rabbit. (Note that the scoops at the ends of the rabbits are filled with water when placed in the HFIR geometry.) 


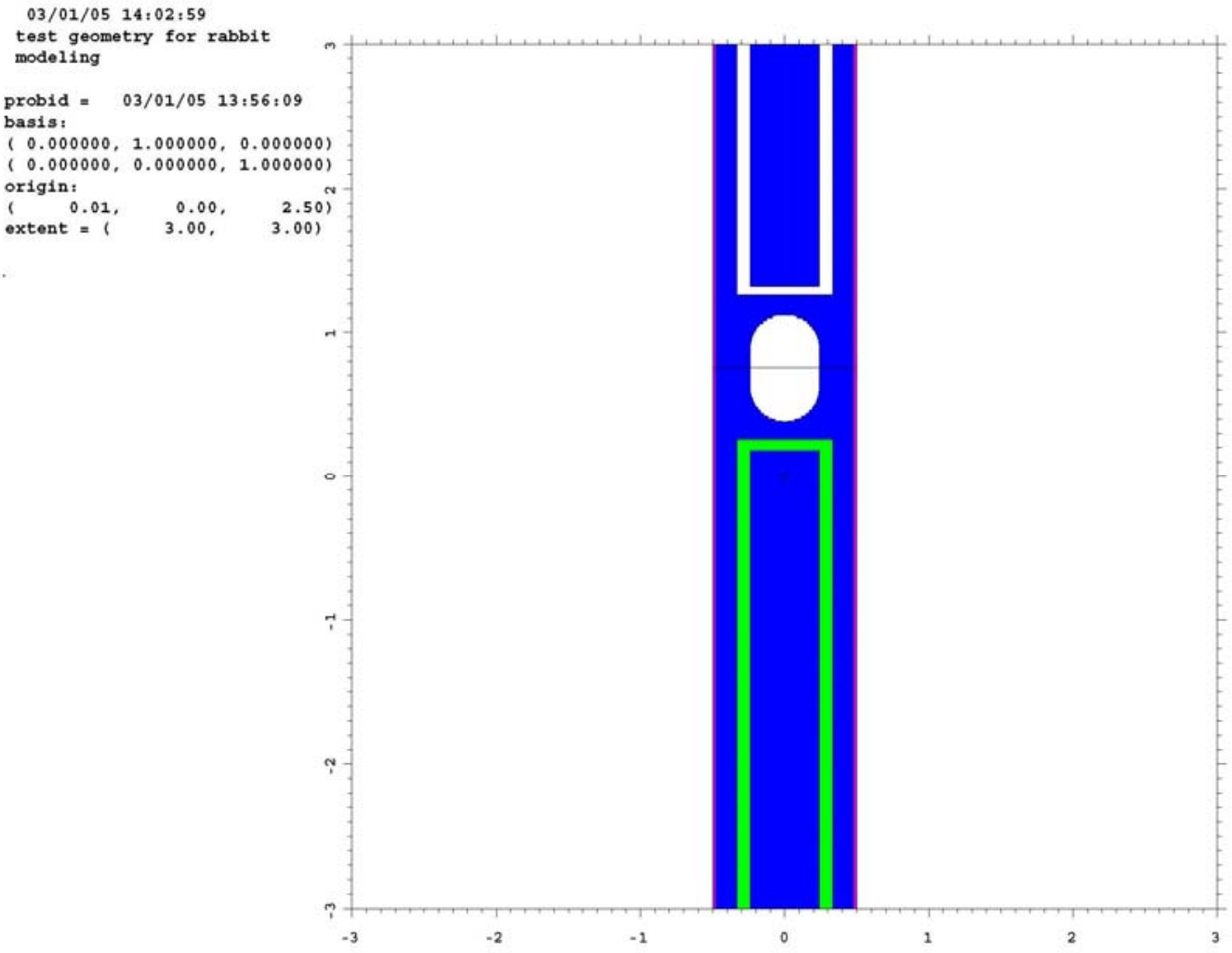

Fig. 9. Close-up plot of the top of the black rabbit and the bottom of the $1 / 3 \mathrm{black}$ rabbit. (Note that the scoops at the ends of the rabbits are filled with water when placed in the HFIR geometry.) 


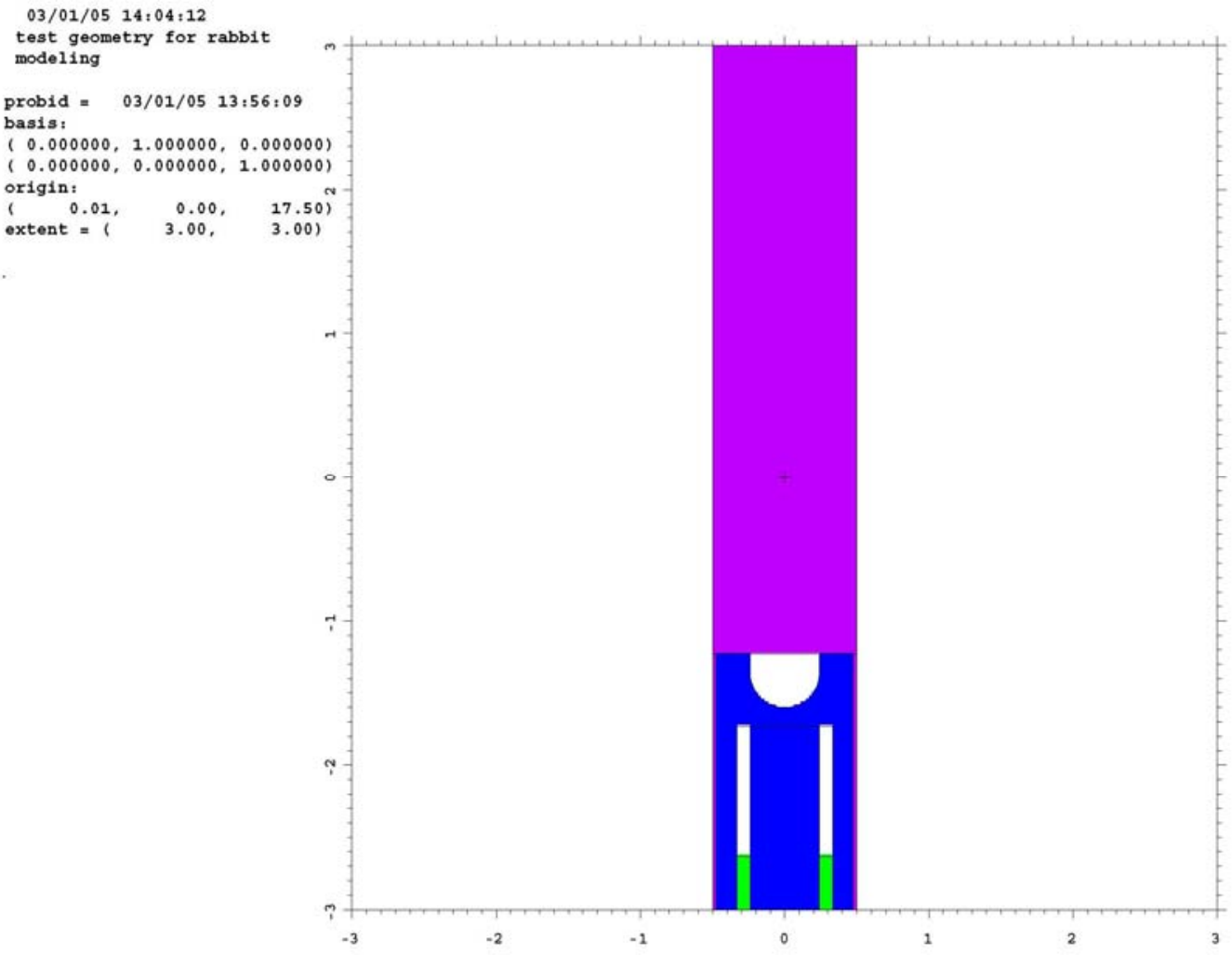

Fig. 10. Close-up plot of the top of the $2 / 3$ black rabbit and the bottom of the all-water "rabbit". (Note that the scoops at the ends of the rabbits are filled with water when placed in the HFIR geometry.) 
03/06/05 11:01:46

HFIR model with Cycle 400

targets (Ejection Expt \#1)

probid $=03 / 06 / 05 \quad 10: 52: 18$

(1.000000,0.000000,0.000000)

$(0.000000,0.000000,1.000000)$

origin:

$\begin{array}{lll}-3.00, & 0.00, & 0.00)^{\circ}\end{array}$

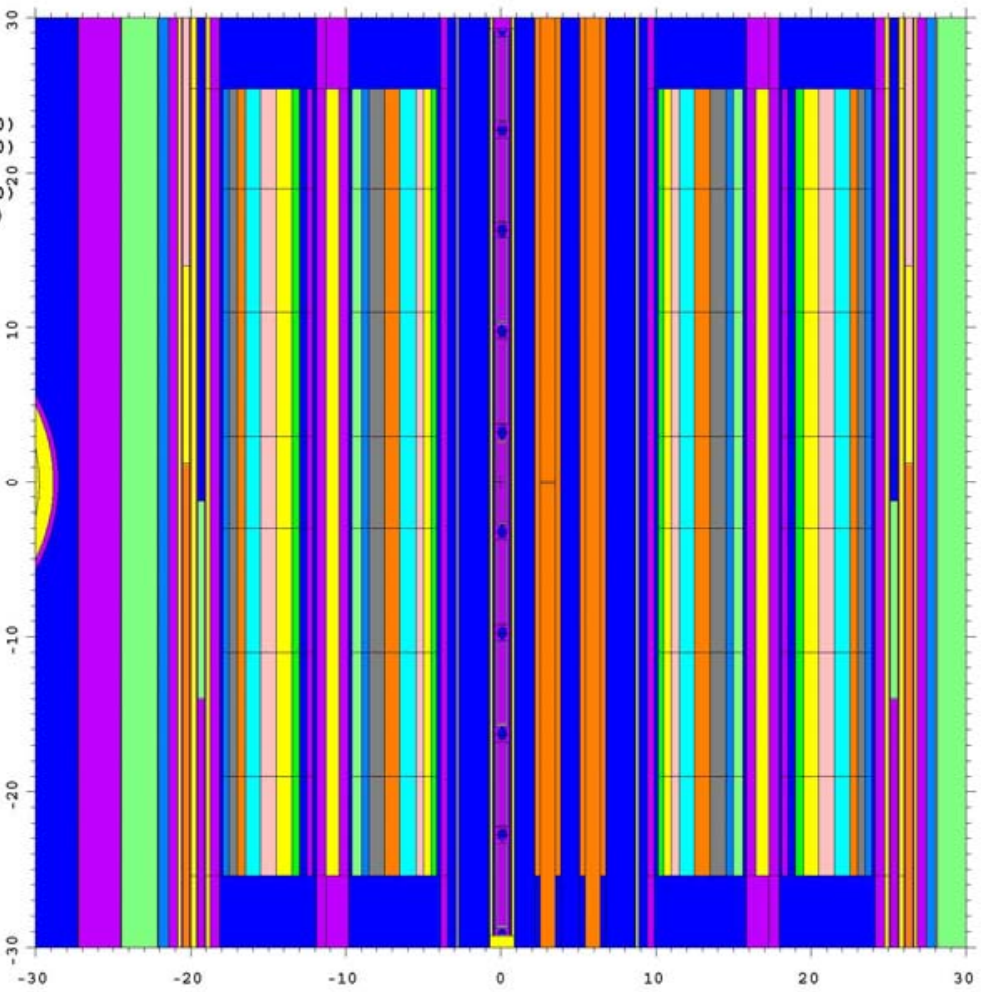

Fig. 11. Elevation plot of the geometry for Ejection Experiment \#1. 
03/06/05 11:03:53

HFIR model with cycle 400

targets (Ejection Expt \#1)

probid $=03 / 06 / 05 \quad 10: 52: 18$

$0.00000,0.000000,0.000000)$

$(0.000000,0.000000,1.000000)$

origin

$\left(\begin{array}{lll}-3.00, & 0.00, & 0.00\end{array}\right)$

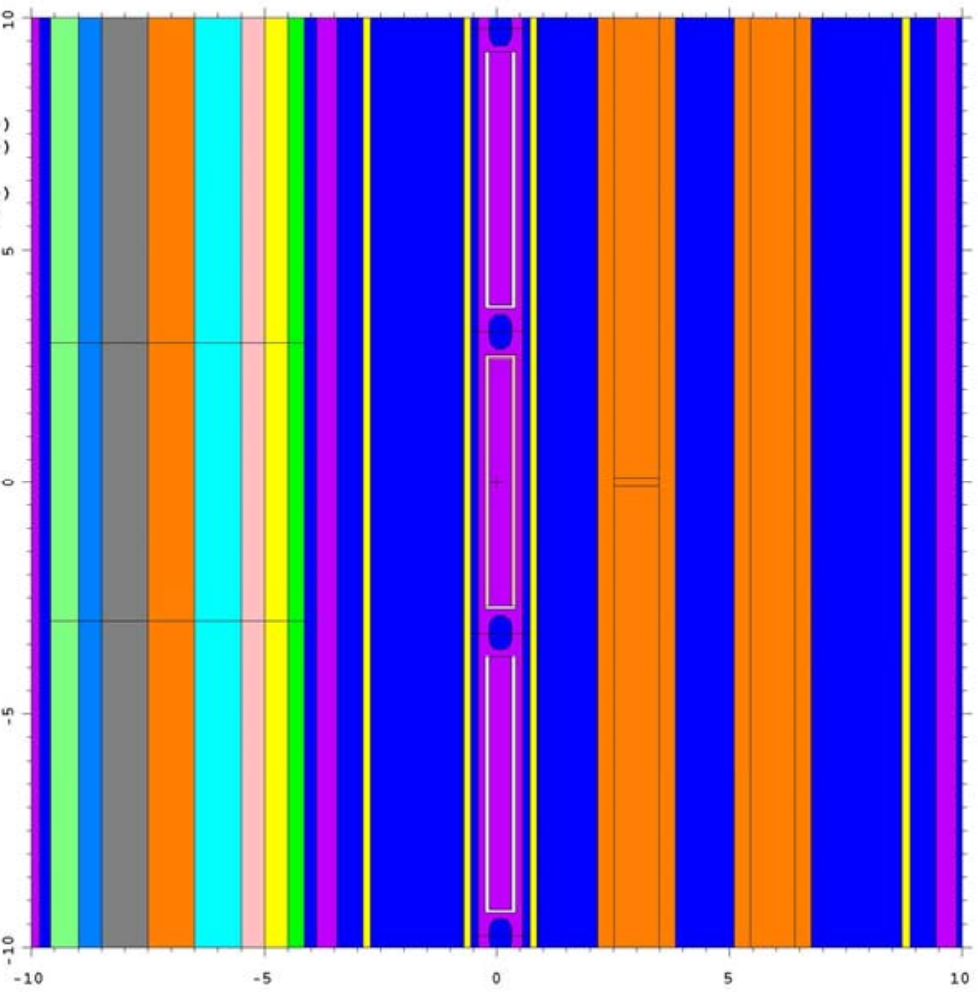

Fig. 12. Close-up plot of the hydraulic tube geometry for Ejection Experiment \#1. 


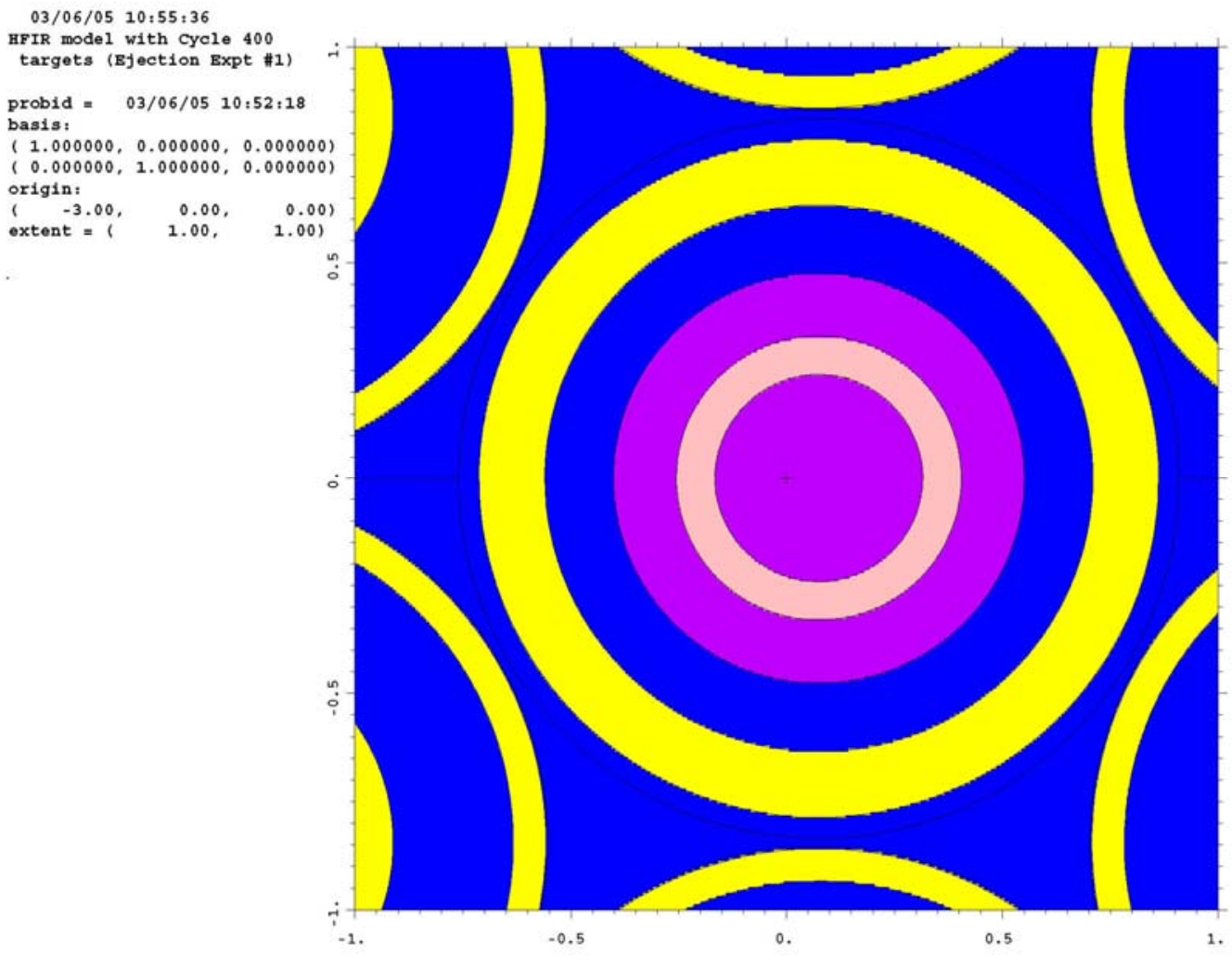

Fig. 13. Plan plot of the hydraulic tube geometry along the axial midplane for Ejection Experiment \#1. 
03/07/05 11:54:45

HFIR model with cycle 400

targets (static Expt \#7)

probid $=03 / 07 / 0511: 48: 19$

$(1.000000,0.000000,0.000000)$

$(0.000000,0.000000,1.000000)$

origin:

( $-3,00$

extent $=(-30.00,-30.00)$

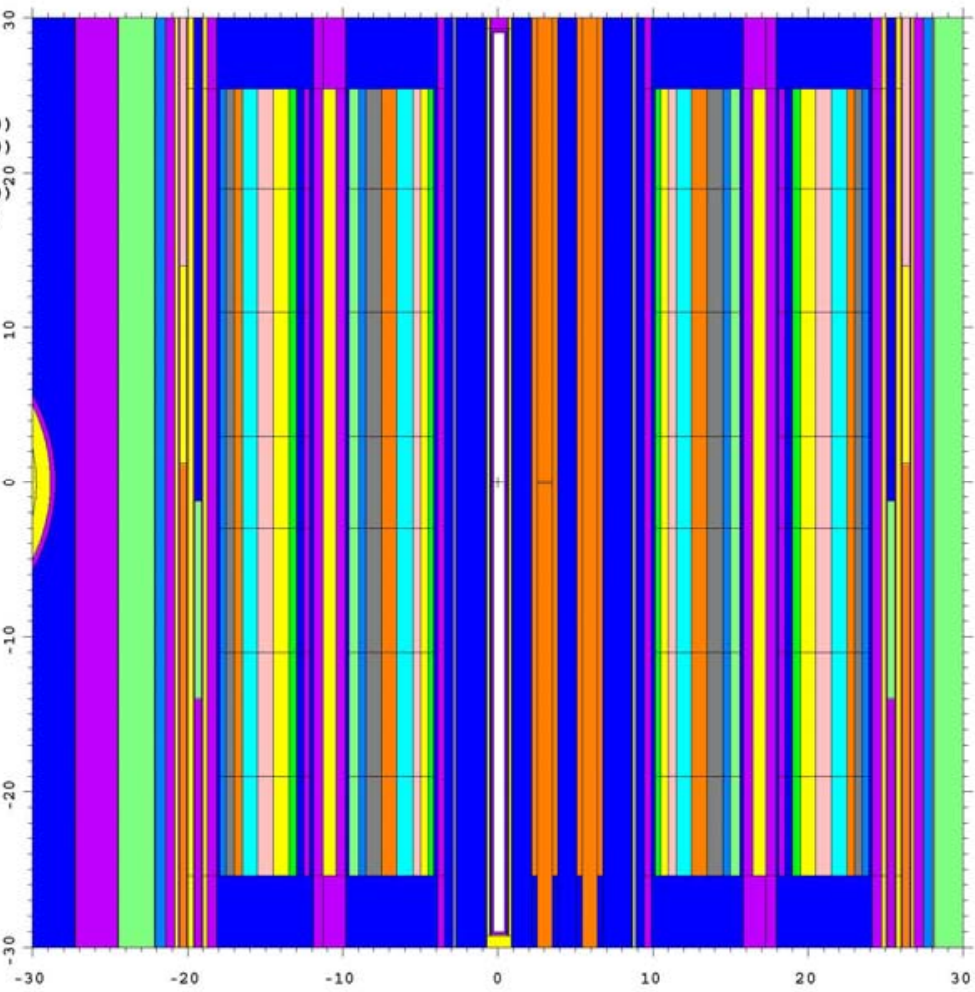

Fig. 14. Elevation plot of the geometry for Static Experiment \#6b. 
03/07/05 11:56:16

HFIR model with cycle 400

targets (static Expt \#7)

probid $=03 / 07 / 0511: 48: 19$

$(1.000000,0.000000,0.000000)$

$(0.000000,1.000000,0.000000)$

origin:

$\left(\begin{array}{lll}-3.00, & 0.00, & 0.00\end{array}\right)$

extent $=1 \quad 1.50, \quad 1.50)$

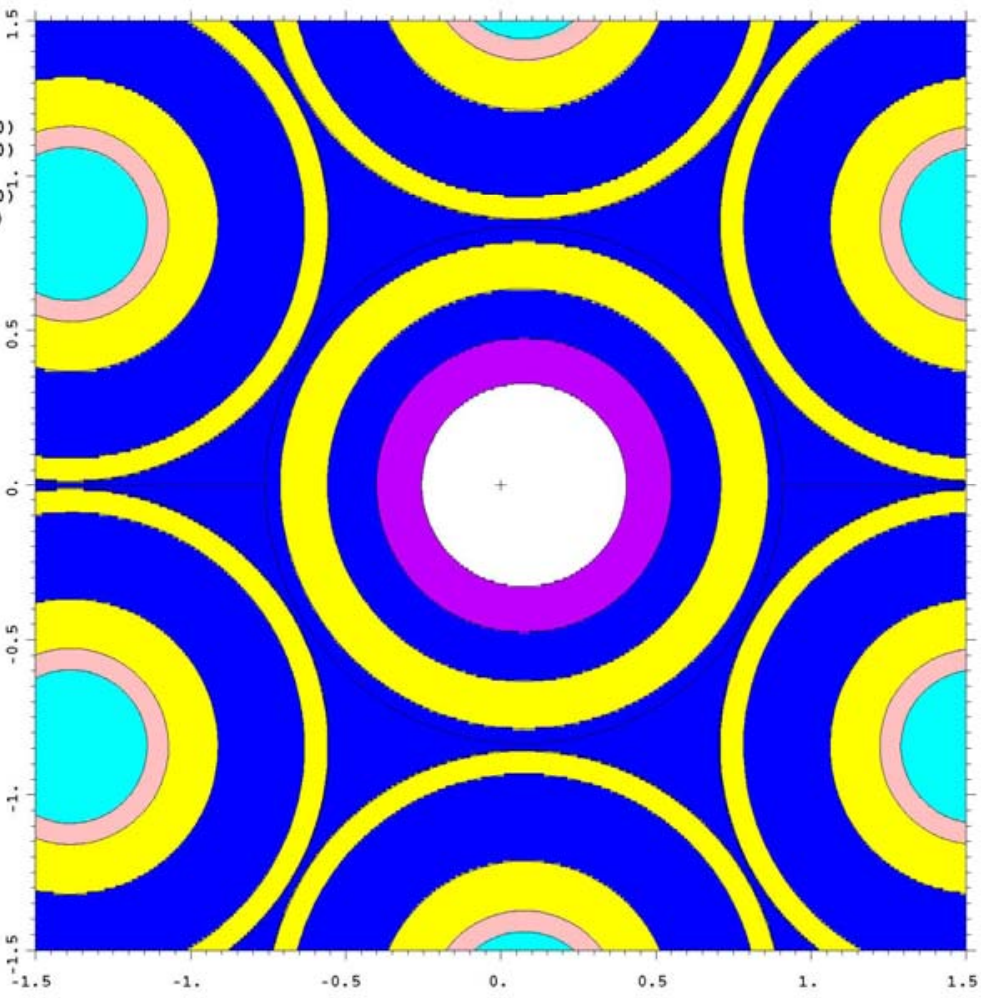

Fig. 15. Plan plot of the hydraulic tube geometry along the axial midplane for Static Experiment \#6b. 
03/07/05 12:27:17

HFIR model with cycle 400

targets (static Expt \#6b)

probid $=03 / 07 / 0512: 22: 01$

$0.000000,0.000000$

$(0.000000,0.000000,1.000000)$

origin:

$\begin{array}{lll}-3.00, & 0.00, & 0.00)^{\circ}\end{array}$

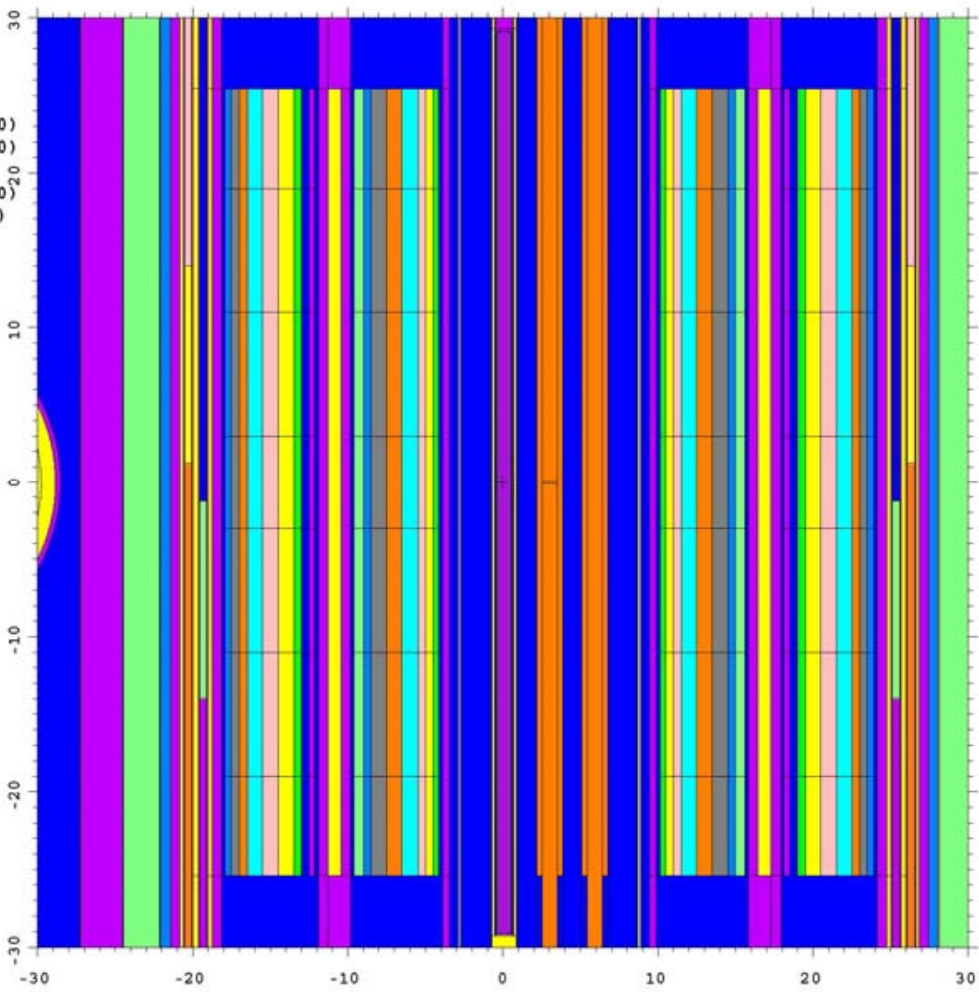

Fig. 16. Elevation plot of the geometry for Static Experiment \#7. 
03/07/05 12:27:35

HFIR model with Cycle 400

targets (static Expt \#6b)

probid $=03 / 07 / 05 \quad 12: 22: 01$

$1.000000,0.000000,0.000000)$

$(0.000000,1.000000,0.000000)$

origin:

$\left(\begin{array}{lll}-3.00, & 0.00, & 0.00\end{array}\right)$

extent $=1 \quad 1.50, \quad 1.50)$

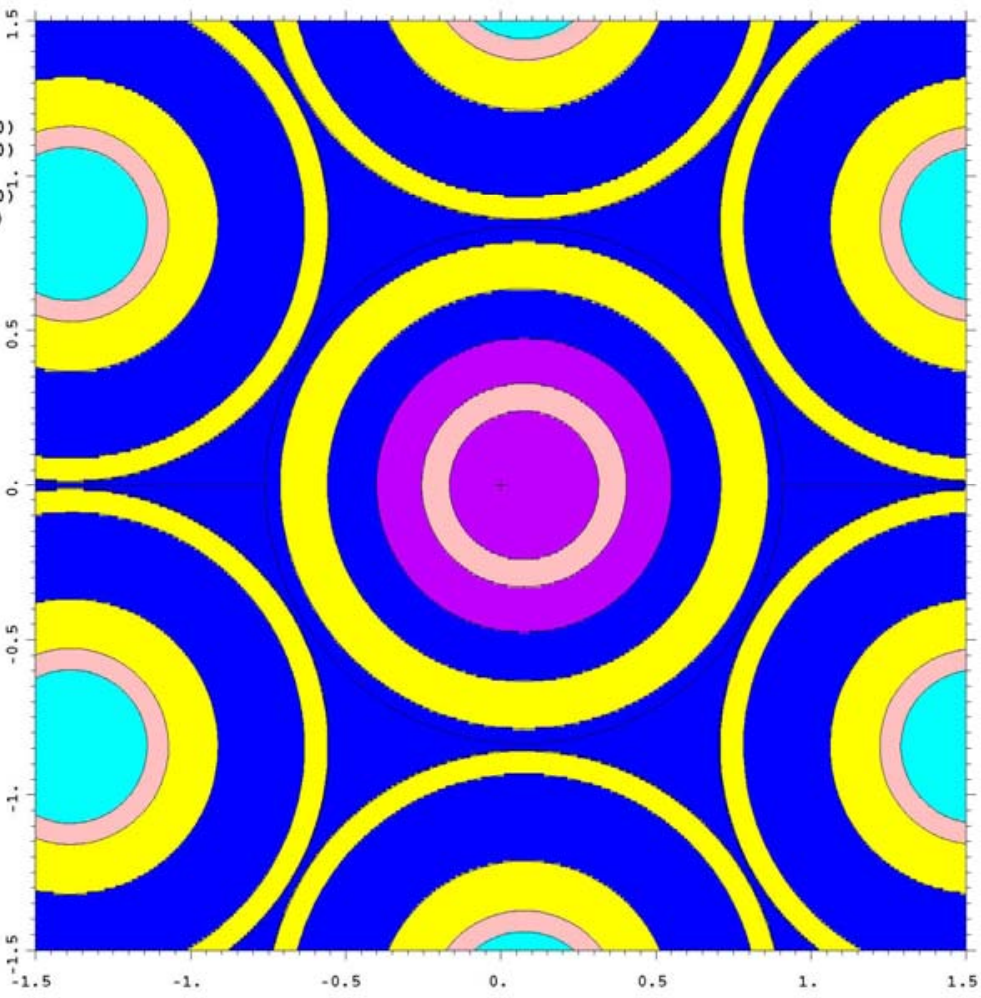

Fig. 17. Plan plot of the hydraulic tube geometry along the axial midplane for Static Experiment \#7. 


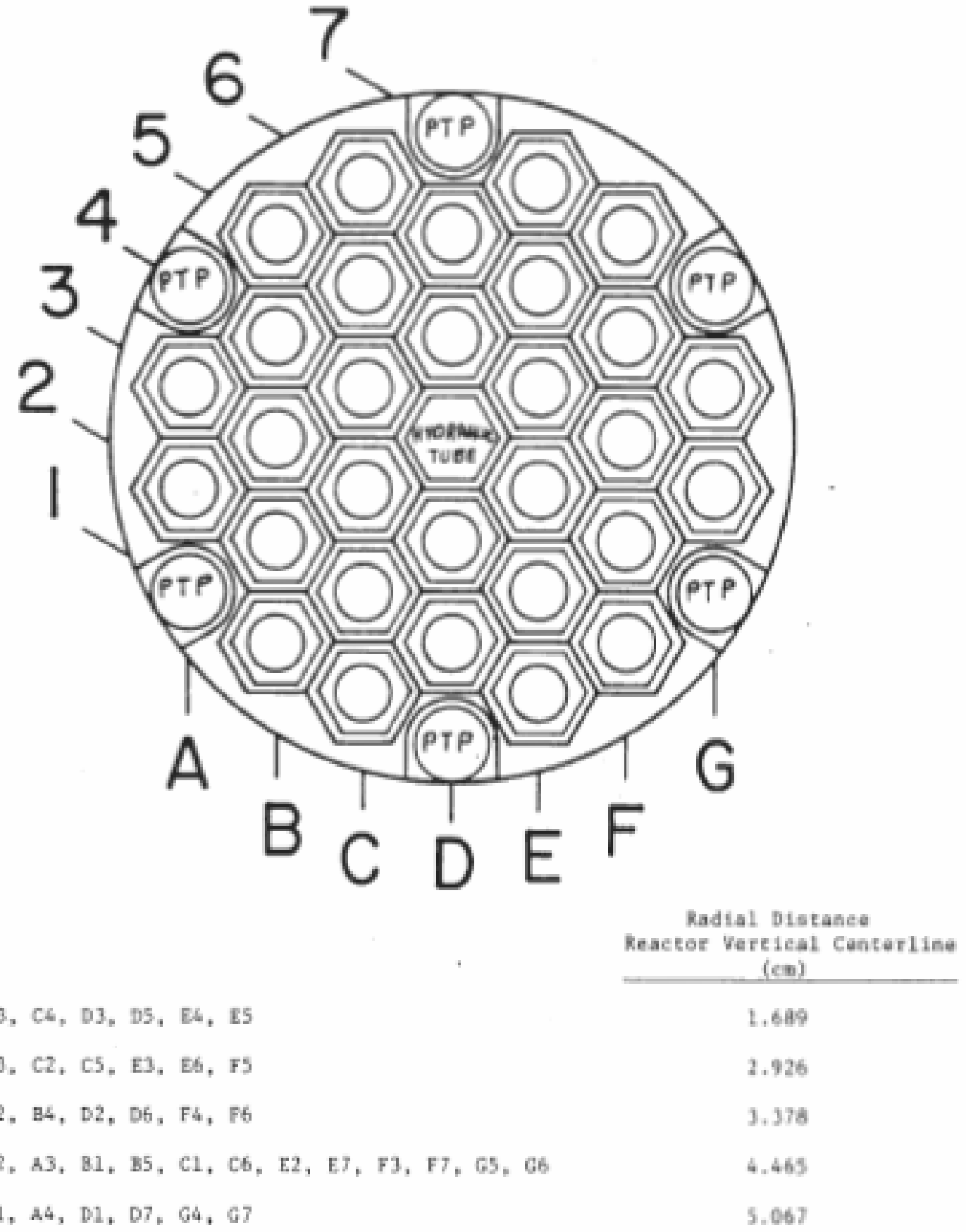

Fig. 18. Original central target configuration for HFIR. 


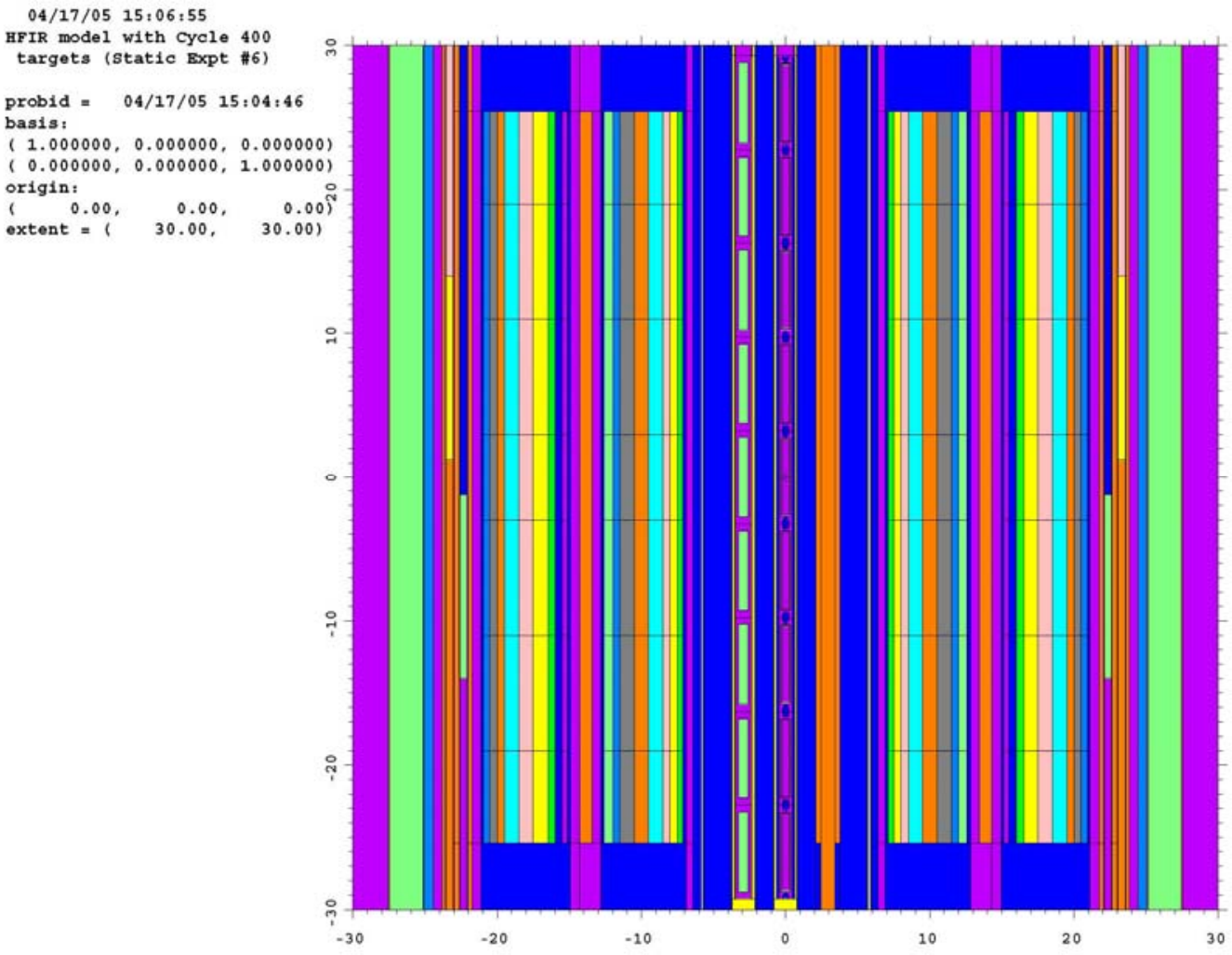

Fig. 19. Elevation plot of the central hydraulic tube geometry for Static Experiment \#6. 


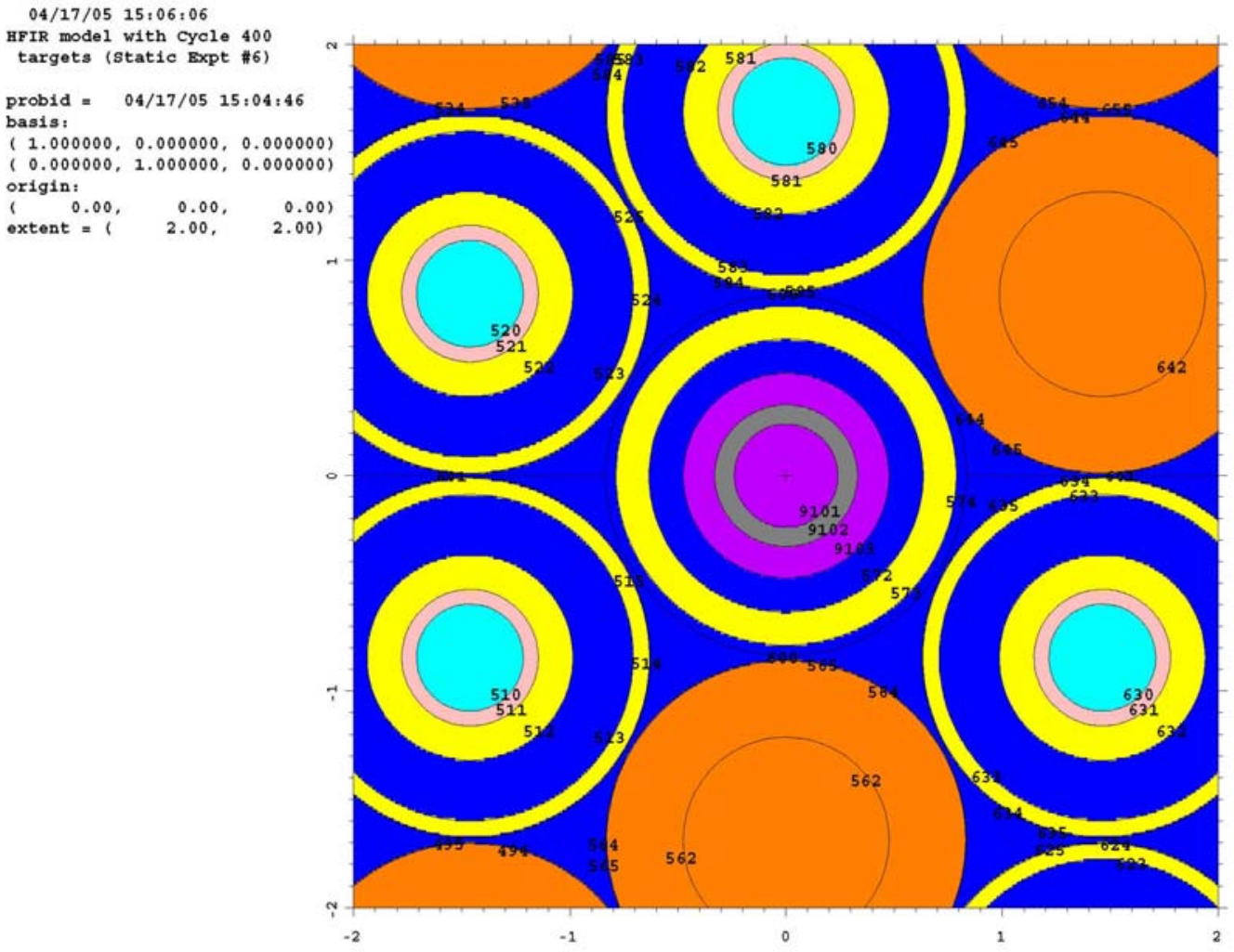

Fig. 20. Plan plot of the central hydraulic tube geometry along the axial midplane for Static Experiment \#6. 
APPENDIX A. T. M. Sims Report on HFIR Reactivity Experiments 

APPENDIX E

\title{
INTRA-LABORATORY CORRESPONDENCE
} OAK RIDGE NATIONAL LABORATORY

March 31, 1967

\author{
To: $\quad$ R. V. McCord \\ From: $\quad$ T. M. Sims \\ Subject: Results of Preliminary Reactivity Experiments - HFIR Hydraulic \\ Tube
}

\section{Introduction}

The main purpose of this letter is to record some of the details of the experiments and the results obtained. The experiments consisted of two parts: (1) a series of critical experiments using single rod mockups simulating various hydraulic tube loads, and (2) a series of hydraulic tube load ejectiọn experiments run at a reactor power level of $\sim 12 \mathrm{Mw}$. In the latter, measurements were made, during ejection of the various loads, of the number 1 safety reset flux vs. time, and the output of the number 1 safety rate network vs. time.

\section{Static Critical Experiments}

The primary purpose of these experiments was to measure the reactivity worths of various simulated loads to provide a basis for establishing the precise sequence for conducting the ejection experiments ${ }^{1}$. Unless indicated otherwise all reactivity worth values reported hereln are relative to the water filled hydraulic tube. Single rod mockups were used to simulate various hydraulic tube loads. Figure 1 shows schematically the configuration of these rods. The black sections indicate "black rabbit" simulators, i.e., they contain 35 mil thick cadmium wrapped completely around an aluminum plug inside an aluminum tube. In that portion of the rods below the black sections, indicated by dashed lines, the metal-to-water ratio is minimized to the extent practical. Thus, the measured worths of these rods closely approximate those of the indicated number of black rabbits, located axially in the facillty as shown in Figure 1. The rod labeled " $9 \mathrm{W"}$ in Figure 1 consisted of a sealed hollow aluminum tube and simulates 9 empty rabbits. The results of the measurements. are given in Figure 2 . Note that the measured worth of the rod simulating 9 black rabbits is $\sim-48 k$ (rod 1n facility relative to water filled facility). This is probably close to the maximum amount of negative reactivity that can be loaded into the (

${ }^{1}$ Prior to these experiments, the differential worth of the regulating rod at 17.450 " was measured using the rod bump technique. The measured value at this position was $\sim \$ 1.58 / 1 \mathrm{n}$. which is in substantial agreement with that given in Figure 5 of CF-65-12-2. This is to be expected since in both cases the measurements were on new rods. Figure 5 of CF-65-12-2 was thus used to determine the reactivity worths of the hydraulic tube loads and load simulators. 
facility with the present rabbits, although it is conceivable that some configurations, e.g., replacement of the aluminum plug around which the cadmium is wrapped with a more effective moderator than aluminum, might result in larger negative worths. Also, larger worths could probably be obtained if the rabbit diameter is inereased.

\section{Ejection Experiments}

Experiments were run in which the reactor power vs. time, and the rate network output vs. time, following the ejection of various loads were measured. The loads were ejected while the reactor was operating at $\sim 12$ Mw. Symmetric critical rod positions were 217.5 in. Figure 3 shows the contents of a typical "black rabbit" and "partial black rabbit". The "white rabbits" used contained solid aluminum plugs and no cadmium. Recorder traces showing $\Delta P$ vs. $t$ (reset flux) and $R$ vs. $t$ (rate network output) associated with the ejection of the indicated loads are shown in Figures 4 through 9. Also shown in these figures is the ratio of the rate hetwork output to the rate trip set point (R/T.S.) vs. time. Nomenclature describing the load configurations is explained in footnote (1) of Table 1 . This table summarizes the measured values of $\Delta P_{\max }$, $\mathrm{dP} / \mathrm{dt})_{\max }{ }^{2} \mathrm{R}_{\max }$, and ( $\mathrm{R}_{\max } /$ rate trip set point) resulting from the ejection of the indicated loads. The values listed in column 2 represent the load worth with the load fully inserted in the facility ${ }^{3}$. Therefore attempts to correlate these values with the associated values of $\left.\Delta \mathrm{P}_{\max }, \mathrm{dP} / \mathrm{dt}\right)_{\max }$, and $\mathrm{R}_{\max }$ will be misleading in some cases because ejection of a particular load does not necessarily correspond to the insertion of the corresponding listed reactivity in a "simple" manner (i.e., in a step or simple ramp). For example, upon ejection of the " $2 / 3 B$ " load, reactivity at first decreases as the rabbit travels toward the core horizontal midplane. This initial decrease is probably compensated to some extent by the servo. Further movement of the rabbit above the horizontal midplane then causes a reactivity increase. The associated $\left.\Delta P_{\max }, \mathrm{dP} / \mathrm{dt}\right)_{\max }$, and $R_{\max }$ values are thus larger than would be expected from the insertion of $1.1 k$ in a simpler manner. It should be noted that no attempt was made to check the reproducibility of the experimental results, since the primary interest was in.covering a fairly wide spectrum of different loads in as short a time as possible. Although the results obtained are more. or less "consistent" it would probably be a good idea to check reproducibility for two or three different loads. For most (but possibly not all) of the loads in Table 1 , application of a factor of 10 to the listed values of $\Delta P_{m}$ $\mathrm{dP} / \mathrm{dt})_{\max }, R_{\max }$, and $R_{\max } / \mathrm{T}$.S. to estimate the effect of load ejection at $100 \mathrm{Mw}$ is probably conservative (i.e., results in an overestimate) for the

\footnotetext{
$\left.{ }^{2} \mathrm{dP} / \mathrm{dt}\right)_{\max }$ obtained from $\Delta \mathrm{P}$ vs. $t$ traces as shown in Figures 4 through 9.

${ }^{3}$ In assessing the accuracy of these values it should be noted that $1 \mathrm{c}$ corresponds to only $0.006 "$ on the regulating rod. On this basis, the accuracy, particularly of the small values, is somewhat questionable.
} 


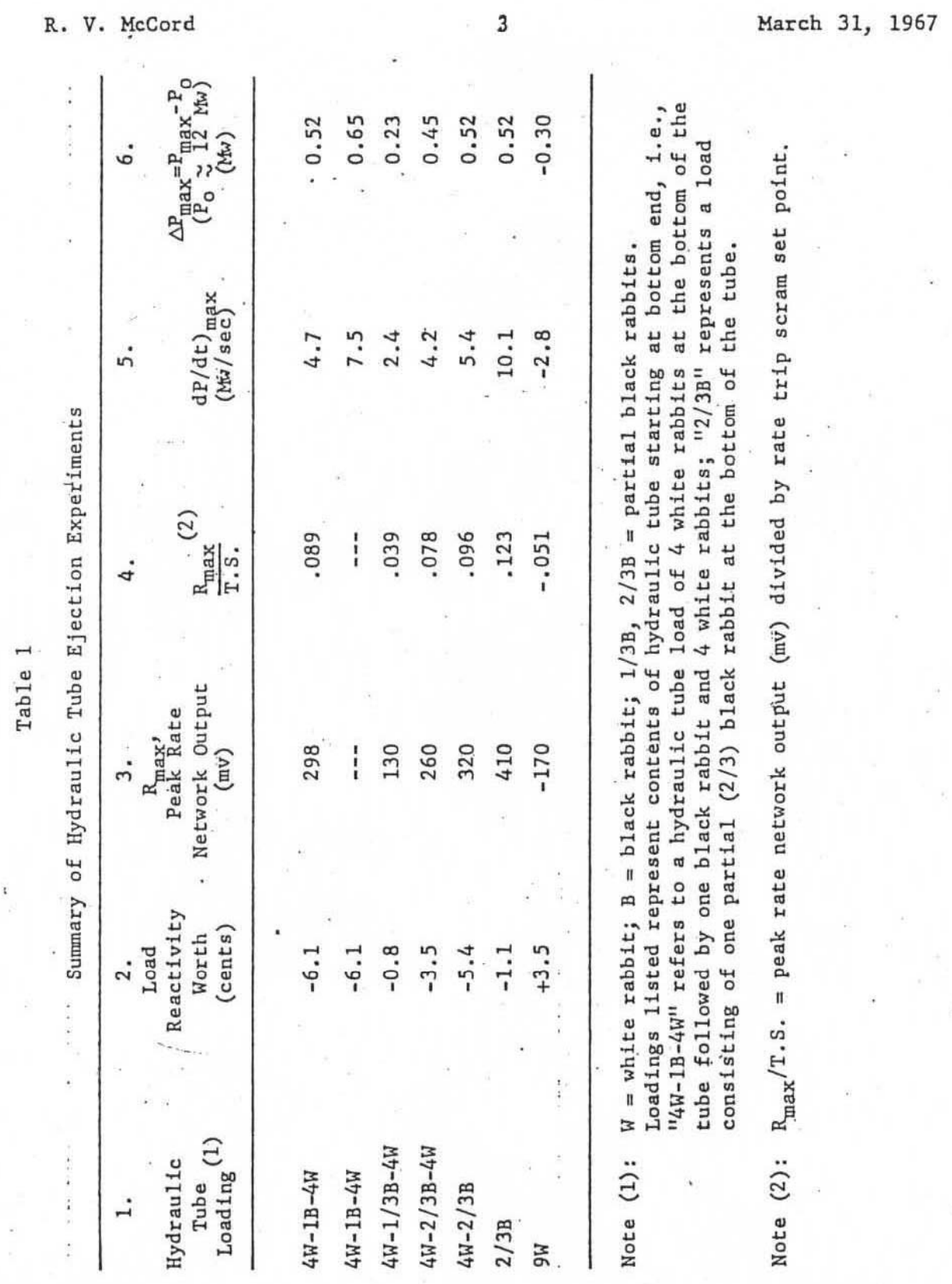


start of cycle condition. However, this may not be the case for other times later in the fuel cycle since the applicable regulating rod differential worth is lower; although just how important this is in limiting the values of $\left.\Delta P_{\max }, d P / d t\right)_{\max }$, and $R_{\max }$ resulting from the ejection of a particular load is not quantitatively known. Further it is not clear that application of a factor of 10 is necessarily conservative for the ejection, at 100 Mw, of the "2/3B" load where, upon ejection, reactivity at first decreases and then increases.

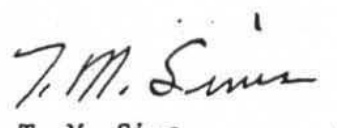

T. M. Sims

TMH: dh

cc: A. L. Boch

C. D. Cagle

T. E. Cole.

R. D. Cheverton

G. J. Dixon

R. V. McCord

G. R. Owens

R. C. Weir ?II 
BY

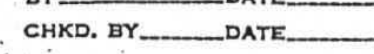

SUBUECT

CHKD. BY

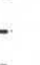

(1)

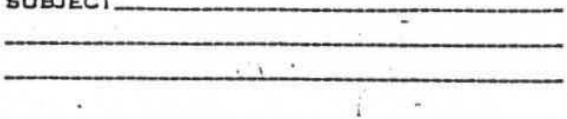

SHEET NO.

JOB NO.

SCHEMATIC CONFIGUPATION - STATIC CRITICAL EXPERIMENT HYDRACLIC TUBE LOADS
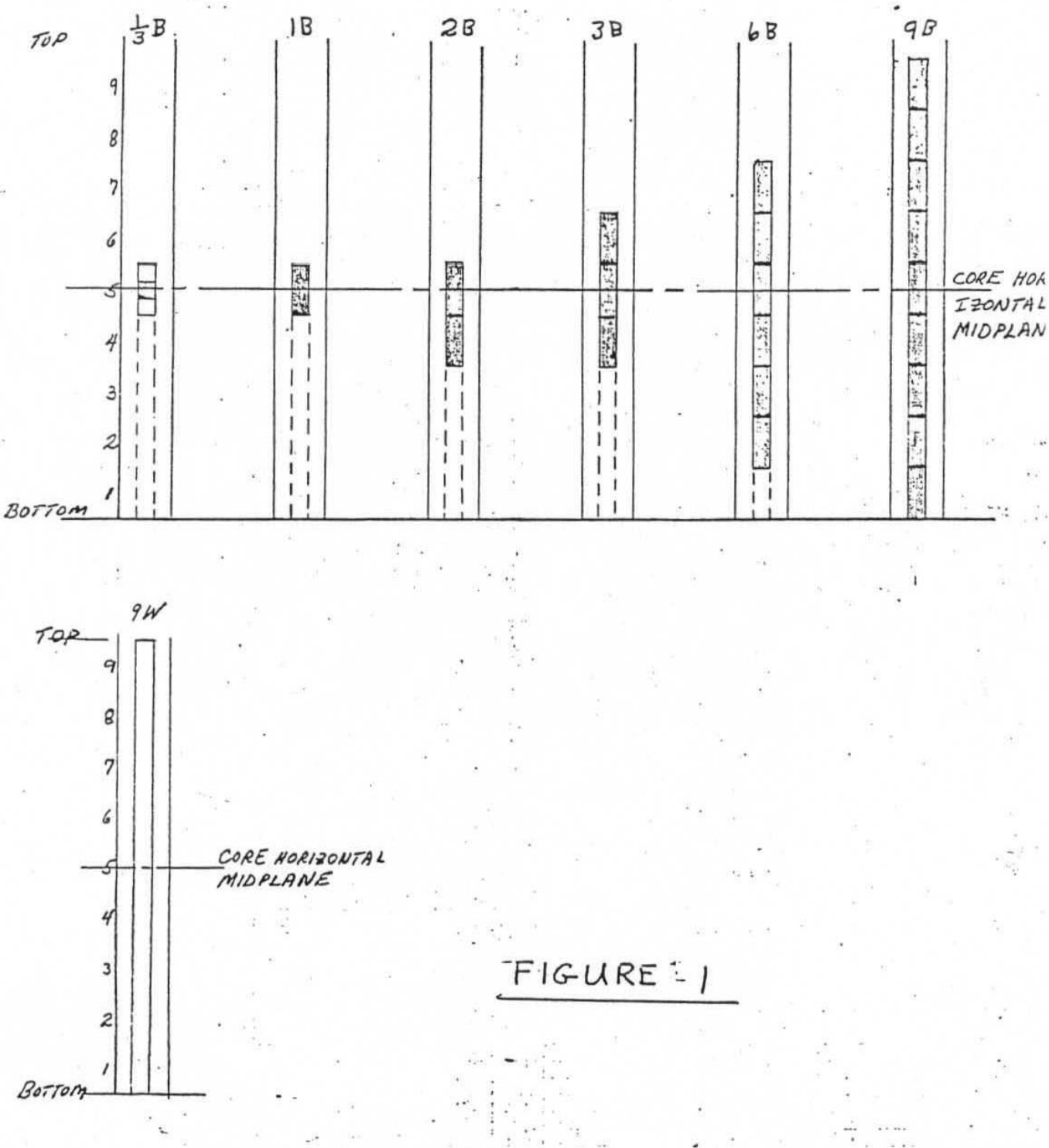

FIGURE - I 


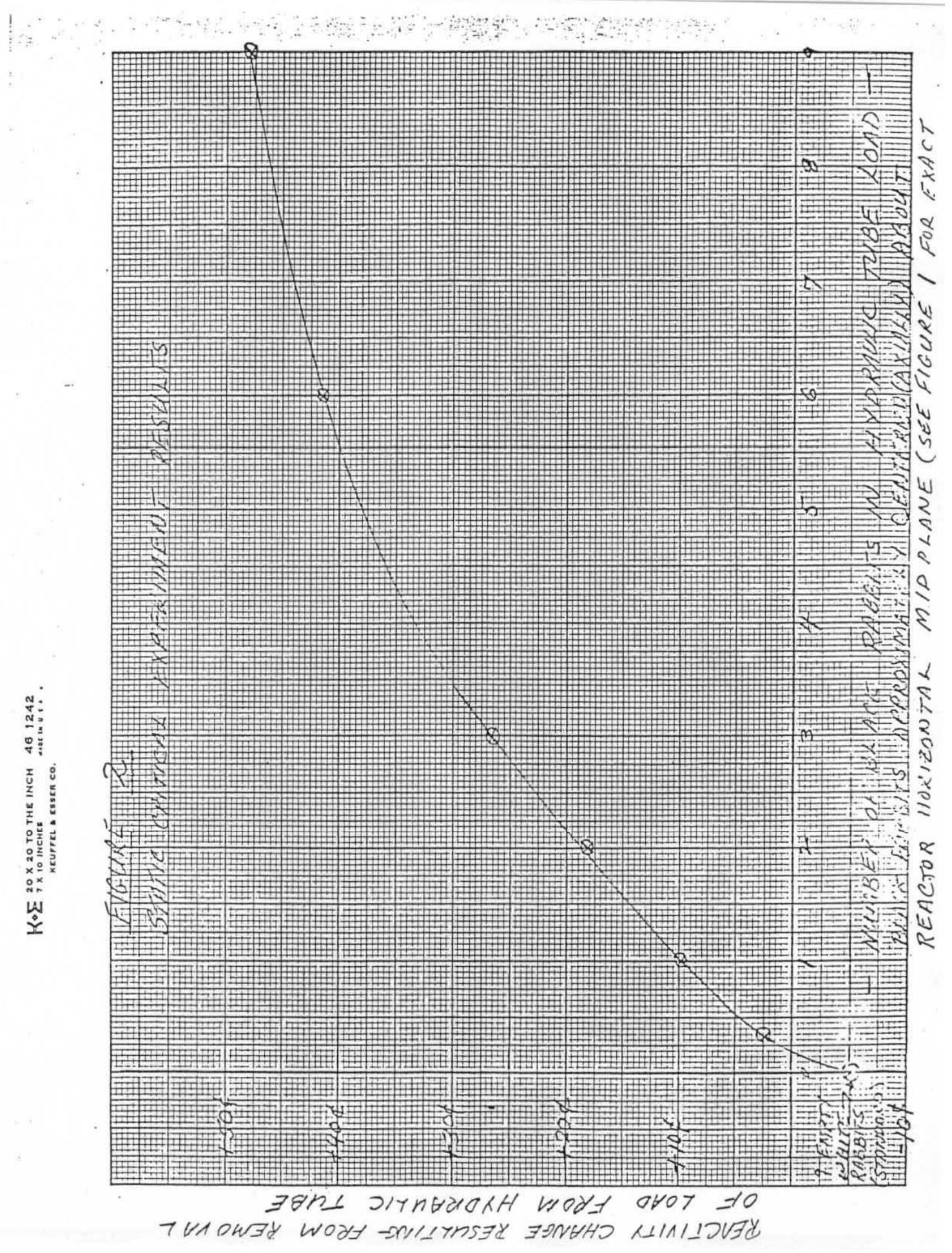




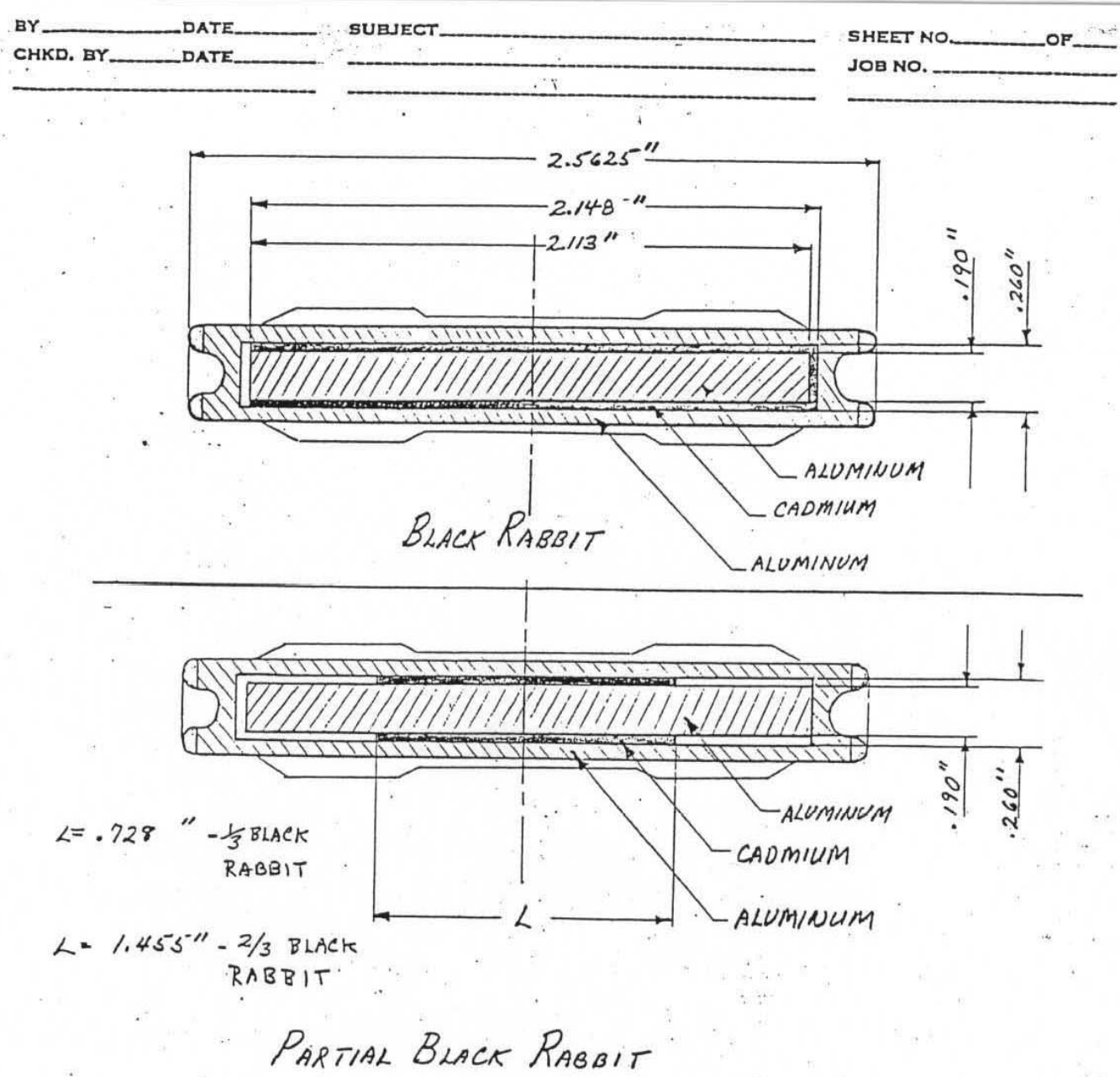

FIGURE 3 


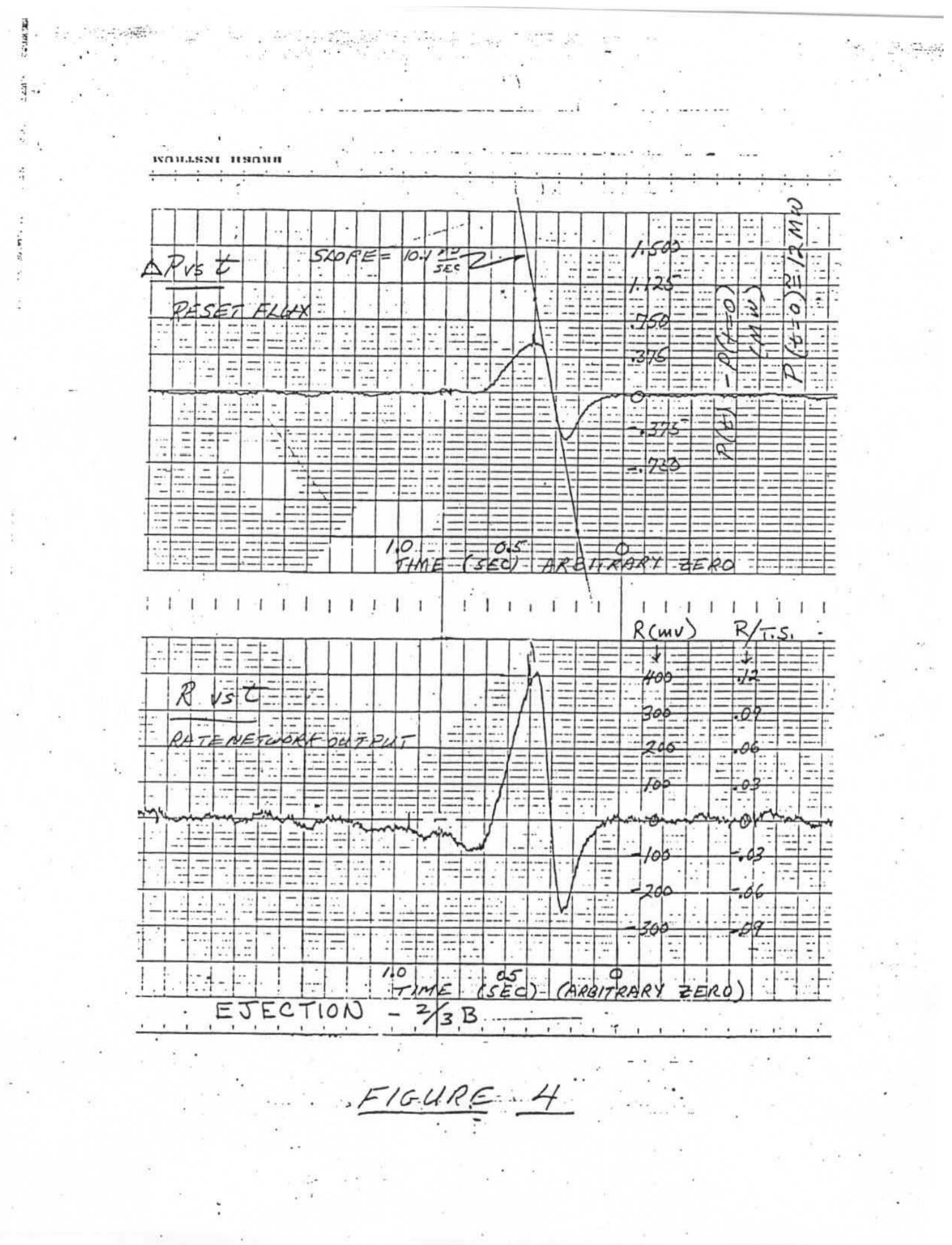




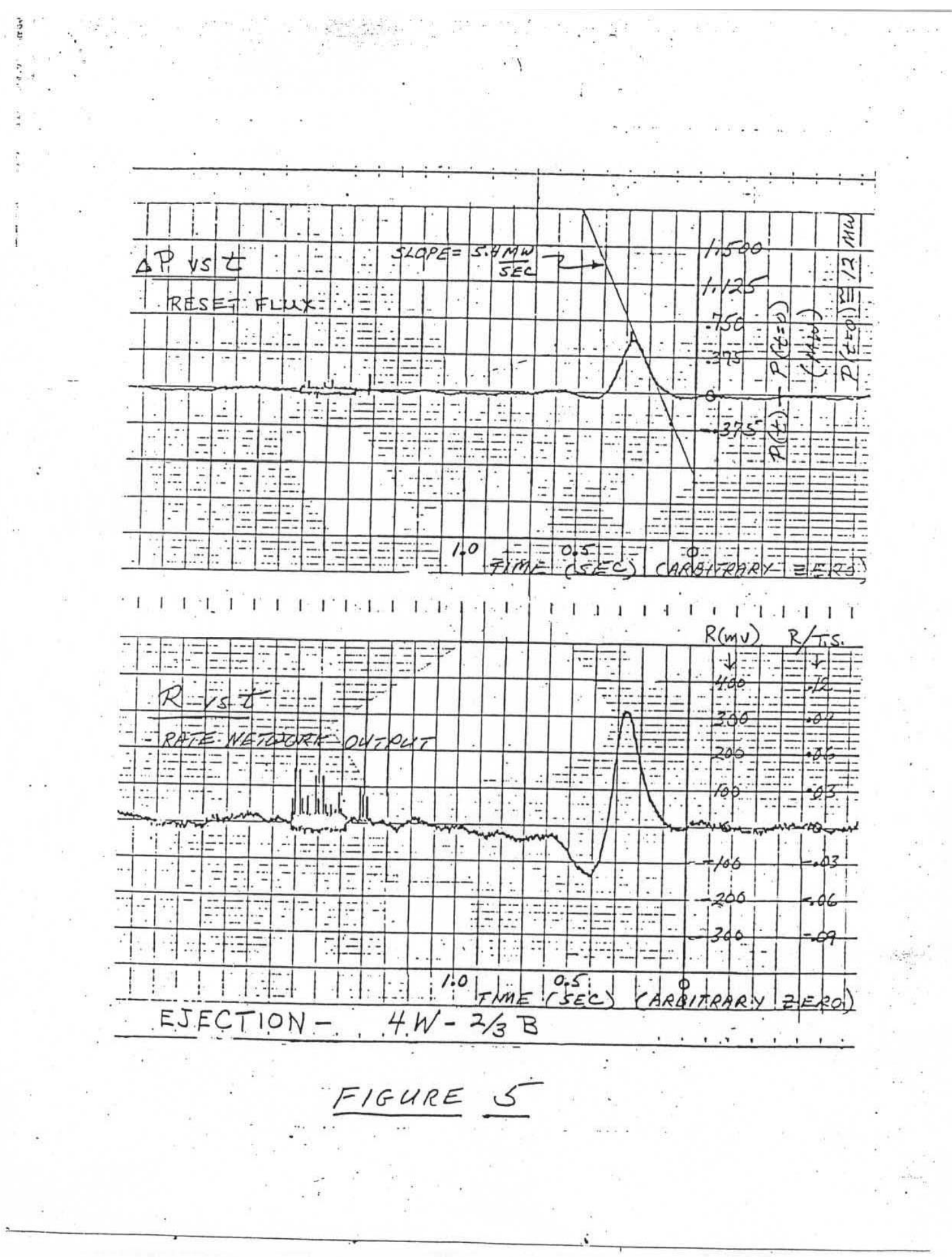



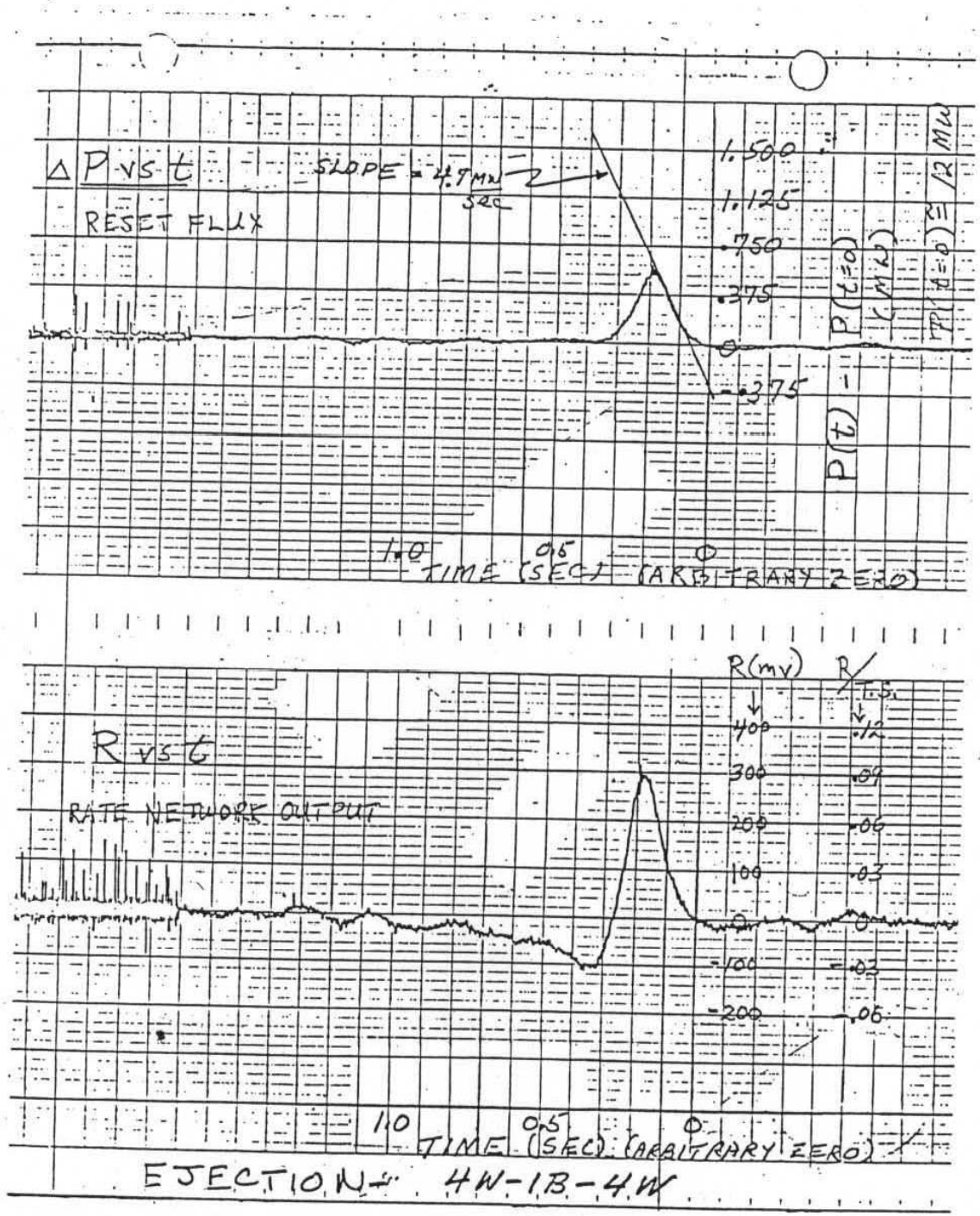

$$
\text { "FIGURE } 6
$$



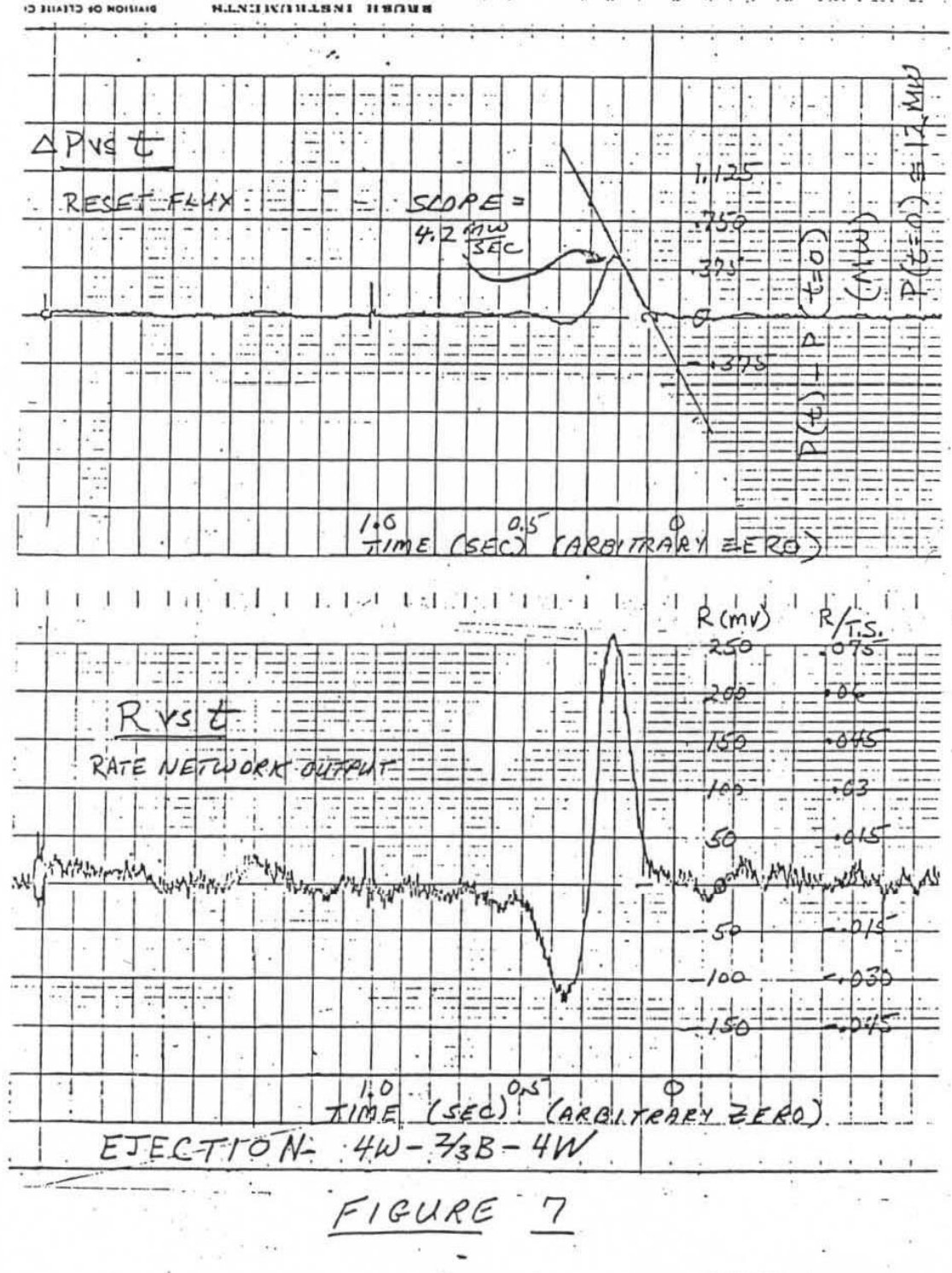


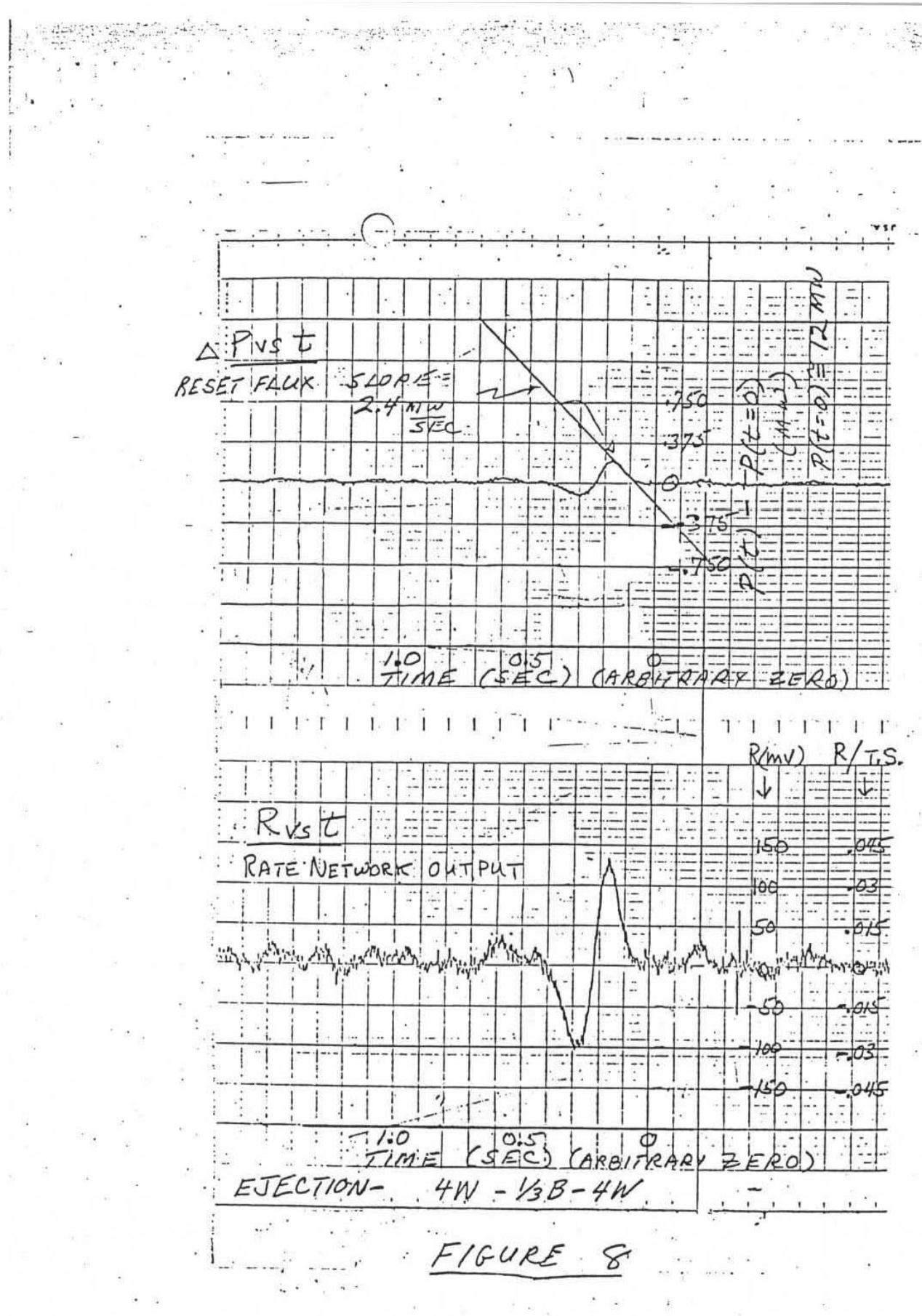




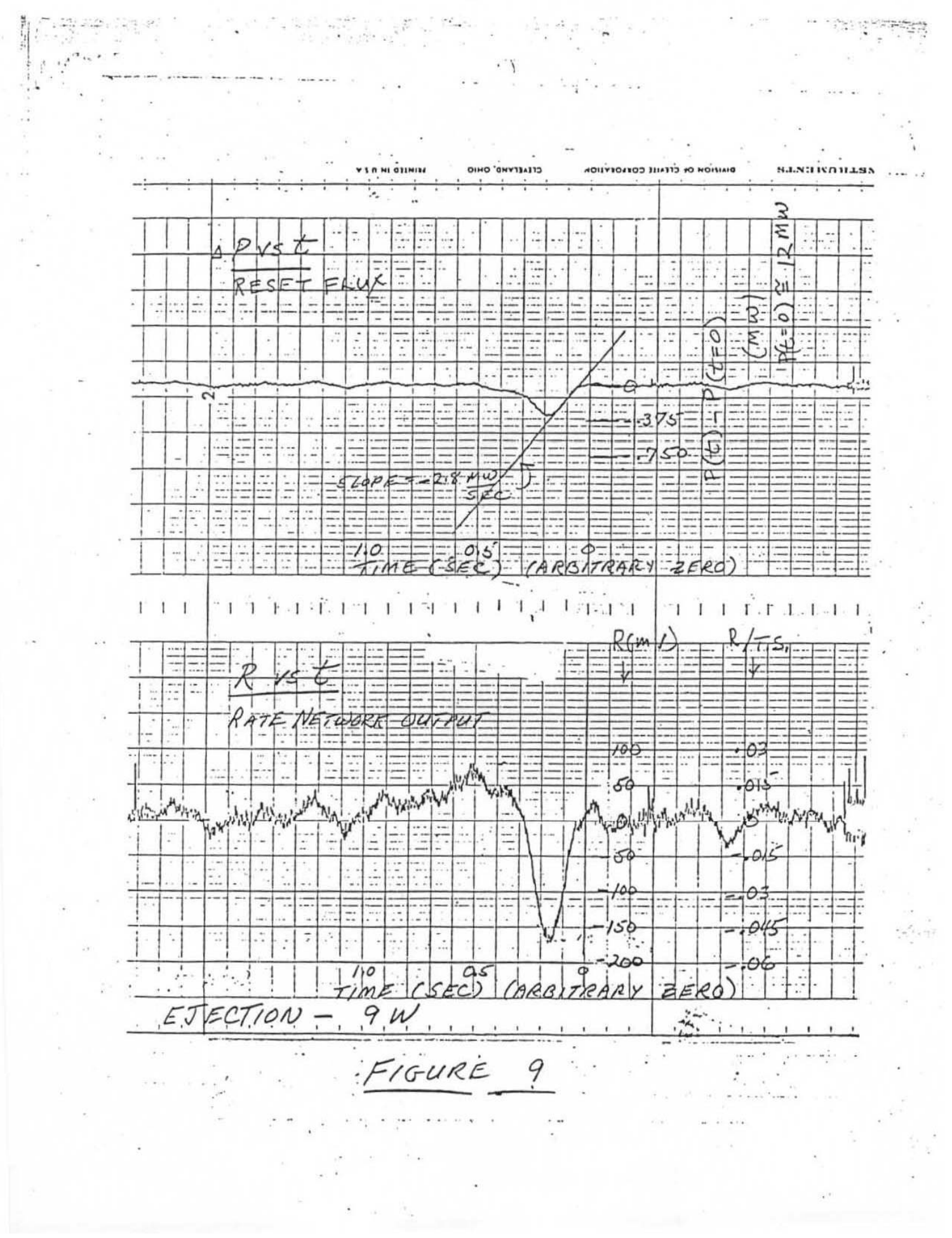



APPENDIX B. Reference Drawings for Rabbit Dimensions 



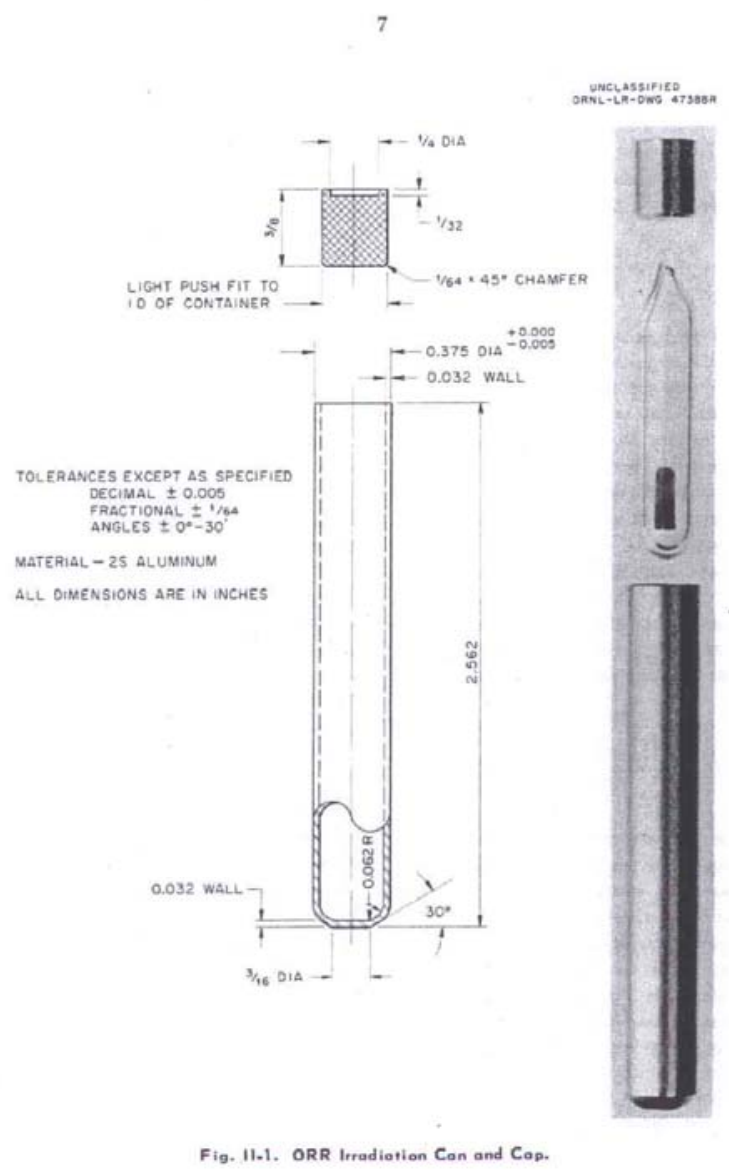

Fig. B1. Irradiation capsule used in the Oak Ridge Research Reactor. 


\section{Hydraulic tube capsule assembly}

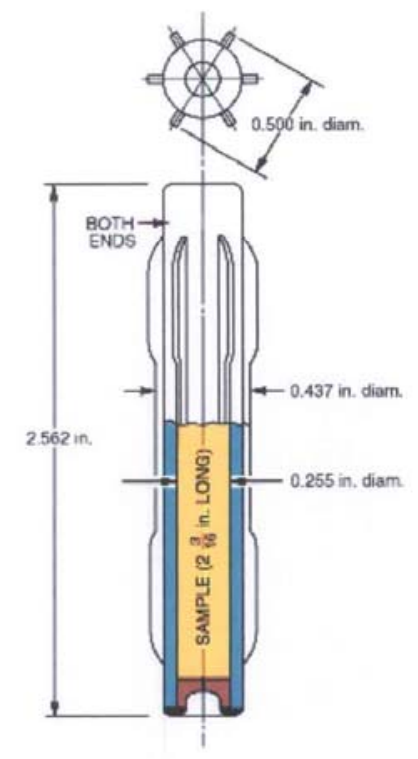

Fig. B2. Capsule used in the HFIR hydraulic tube experiments. 
APPENDIX C. Descriptions of Input and Output Files for the Rabbit Worth Calculations 

The table below matches the input and output files to the experiments. The output files have the letter "o" following the input file name and the tally files have the letter " $\mathrm{m}$ " following the input file name. The log files have the letter "l" preceding the input file name. It is in the log files where the "final k" values are printed with the nine decimal digits. There are only five digits in the output file. The Fortran source for the subroutine modified to print more digits for the "final k" (crit1_mod.F90) was mentioned in the main text. In addition, the files hfv400a and hfv400b were used to calculate the fission and aluminum capture rates that were used to compare two calculational models. The first file is for the Xoubi model (Ref. C1), and the second is for the Peplow model (Ref. C2) with the Cycle 400 target model from Ref. C1 incorporated. Unlike the input files for the rabbit calculations, the materials in the hfv $400 \mathrm{~b}$ file were not all ENDFB6, yet calculated results agreed well for both models.

\section{MCNP5 Input and output files for the experimental mockups within the HFIR hydraulic tube}

\begin{tabular}{|c|c|c|c|}
\hline Experiment & Description $^{a}$ & Input File Name & Output File Name \\
\hline \multicolumn{4}{|c|}{ Ejection Experiments } \\
\hline 0 & $9 \mathrm{H} 2 \mathrm{O}$ & hfv400d & hfv400do \\
\hline 1 & 4W1-1B-4W1 & hfv400c & hfv400co \\
\hline $1 \mathrm{~b}$ & 4W2-1B-4W2 & $\mathrm{hfv} 400 \mathrm{j}$ & hfv400jo \\
\hline 2 & 4W1-1/3B-4W1 & hfv400e & hfv400eo \\
\hline 3 & 4W1-2/3B-4W1 & hfv400f & hfv400fo \\
\hline 4 & 4W1-2/3B-4H2O & hfv400g & hfv400go \\
\hline 5 & $2 / 3 \mathrm{~B}-8 \mathrm{H} 2 \mathrm{O}$ & hfv400h & hfv400ho \\
\hline 6 & $9 \mathrm{~W} 1$ & hfv400i & hfv400io \\
\hline $6 \mathrm{~b}$ & 9W2 & hfv400k & hfv400ko \\
\hline \multicolumn{4}{|c|}{ Static Experiments } \\
\hline 0 & $9 \mathrm{H} 2 \mathrm{O}$ & hfv400d & hfv400do \\
\hline 1 & $4 \mathrm{H} 2 \mathrm{O}-1 / 3 \mathrm{~B}-4 \mathrm{H} 2 \mathrm{O}$ & hfv4001 & hfv4001o \\
\hline 2 & $4 \mathrm{H} 2 \mathrm{O}-1 \mathrm{~B}-4 \mathrm{H} 2 \mathrm{O}$ & hfv400m & hfv400mo \\
\hline 3 & $3 \mathrm{H} 2 \mathrm{O}-2 \mathrm{~B}-4 \mathrm{H} 2 \mathrm{O}$ & hfv400n & hfv400no \\
\hline 4 & $3 \mathrm{H} 2 \mathrm{O}-3 \mathrm{~B}-3 \mathrm{H} 2 \mathrm{O}$ & hfv400o & hfv400oo \\
\hline 5 & $1 \mathrm{H} 2 \mathrm{O}-6 \mathrm{~B}-2 \mathrm{H} 2 \mathrm{O}$ & hfv400p & hfv400po \\
\hline 6 & $9 \mathrm{~B}$ & hfv400q & hfv400qo \\
\hline $6 \mathrm{~b}$ & "9B" & hfv400s & hfv400so \\
\hline 7 & "9W" & hfv400r & hfv400ro \\
\hline 6 (central tube) & 9B & hfv $400 t$ & hfv400to \\
\hline 0 (central tube) & $9 \mathrm{H} 2 \mathrm{O}$ & hfv400u & hfv400uo \\
\hline
\end{tabular}

${ }^{a}$ The components are as follows:

H2O: All-water rabbits that are $6.50748 \mathrm{~cm}$ long.

W1: White rabbits that are $6.50748 \mathrm{~cm}$ long with aluminum plug inside.

W2: White rabbits that are $6.50748 \mathrm{~cm}$ long with voided inside.

B: Black rabbits that are $6.50748 \mathrm{~cm}$ long containing a plug of cadmium over aluminum.

1/3B: Partially black rabbits that are $6.50748 \mathrm{~cm}$ long containing a plug having a $1.84912-\mathrm{cm}$-wide cadmium sheet around a $5.45592-\mathrm{cm}$-long aluminum rod.

2/3B: Partially black rabbits that are 6.50748 -cm-long containing a plug having a $3.6957-\mathrm{cm}$-wide cadmium sheet around a 5.45592-cm-long aluminum rod.

"9B": A plug simulating nine black rabbits with a 58.56732-cm-long aluminum tube plugged with a cadmium sheet surrounding a 58.27522-cm-long aluminum rod.

"9W": A plug simulating nine white rabbits with a 58.56732 -cm-long aluminum tube containing a 58.27522-cm-long void chamber. 


\section{REFERENCES}

C1. N. Xoubi and R. T. Primm III, 3-D MCNP Model and Benchmarking of the High Flux Isotope Reactor Cycle 400, ORNL/TM-2004/251.

C2. D. E. Peplow, A Computational Model of the High Flux Isotope Reactor for the Calculations of Cold Source, Beam Tube, and Guide Hall Nuclear Parameters, ORNL/TM-2004/237, November 2004. 
ORNL/TM-2005/94

\section{INTERNAL DISTRIBUTION}

1. C. W. Alexander

2. F. A. Alpan

3. L. W. Boyd

4. E. D. Blakeman

5. J. A. Bucholz

6. S. E. Burnette

7. D. H. Cook

8. M. B. Farrar

9. J. D. Freels

10. F. X. Gallmeier

11. J. C. Gehin

12. G. J. Hirtz

13. R. W. Hobbs

14. J. O. Johnson

15. R. A. Lillie
16. D. J. Newland

17. C. V. Parks

18. D. E. Peplow

19-21. R. T. Primm III

22. I. Remec

23. J. P. Renier

24. D. L. Selby

25-29. C. O. Slater

30. K. A. Smith

31. C. C. Southmayd

32. H. R. Vogel

33. RRD Document Control Center

34. ORNL Laboratory Records

\section{EXTERNAL DISTRIBUTION}

35. R. D. Cheverton, 2703 West Gallaher Ferry Road, Knoxville, TN 37923

36. Lap-Yan Cheng, Mail Stop 475B, Brookhaven National Laboratory, Upton, New York 11973-5000

37. Dr. Hans D. Gougar, Manager, Fission and Fusion Systems, INEEL, P.O. Box 1625, MS 3860, Idaho Falls, ID 83415-3860

38. M. Huttmaker, Office of Nuclear Energy, NE-40-GTN, Department of Energy, Germantown, MD 20874-1290

39. Dr. D. Kutikkad, University of Missouri Research Reactor Facility, Columbia, Missouri 65211

40. Dr. J. C. McKibben, University of Missouri Research Reactor Facility, Columbia, Missouri 65211

41. G. J. Malosh, ORNL Site Office, Department of Energy, Oak Ridge National Laboratory, Oak Ridge, Tennessee 37831-6269

42. J. O. Moore, ORNL Site Office, Department of Energy, Oak Ridge National Laboratory, Oak Ridge, Tennessee 37831-6269

43. Thomas Newton, MIT Nuclear Reactor Laboratory, 138 Albany Street, Cambridge, MA 02139

44. R. D. Rothrock, 705 Cordova Lane, Lenoir City, TN 37771

45. L. A. Smith, Nuclear Fuels Department, Entergy Services, Inc., 1340 Echelon Parkway, Jackson, Mississippi 39213

46. Dr. R. E. Williams, NIST Center for Neutron Research, 100 Bureau Drive, Stop 8560, Gaithersburg, MD 20899 